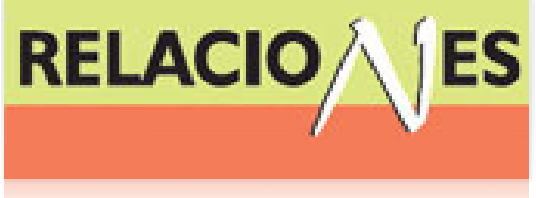

Relaciones. Estudios de historia y sociedad ISSN: 0185-3929

relacion@colmich.edu.mx

El Colegio de Michoacán, A.C

México

Roskamp, Hans; Monzón, Cristina

Usos y abusos de un uhcambeti en Tzirosto, Michoacán, siglo XVI: el caso de Cristóbal Tzurequi Relaciones. Estudios de historia y sociedad, vol. XXXII, núm. 128, 2011, pp. 245-287

El Colegio de Michoacán, A.C

Zamora, México

Disponible en: http://www.redalyc.org/articulo.oa?id=13721074007

Cómo citar el artículo

- Número completo

- Más información del artículo

Página de la revista en redalyc.org

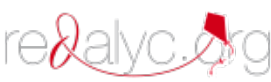

Sistema de Información Científica

Red de Revistas Científicas de América Latina, el Caribe, España y Portugal Proyecto académico sin fines de lucro, desarrollado bajo la iniciativa de acceso abierto 
SECCIÓN GENERAL

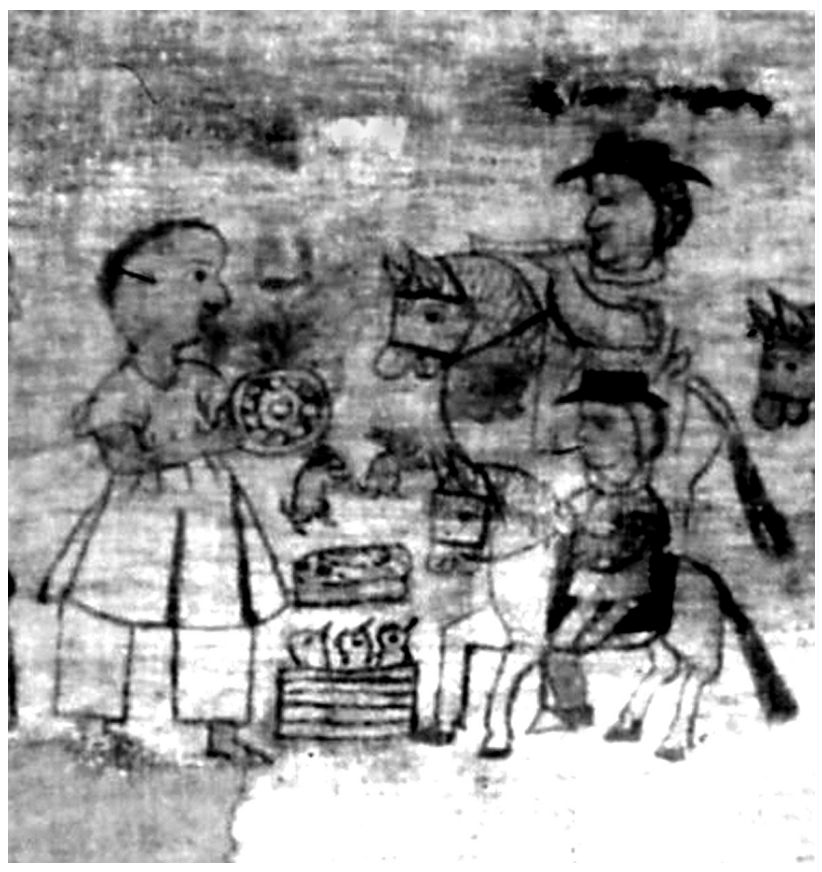




\title{
Usos y abusos de un uhcambeti en Tzirosto, Michoacán, siglo Xvi: el caso de Cristóbal Tzurequi
}

\author{
Hans Roskamp \\ Cristina Monzón* \\ EL COLEGIO DE MICHOACÁN
}

El presente artículo contiene el análisis histórico de un documento en lengua tarasca que fue redactado en 1563 por el escribano de la república de indios de Santa Ana Tzirosto y que trata de los supuestos abusos cometidos por el uhcambeti o mandón del asentamiento sujeto de San Francisco Corupo. Este personaje local gozaba del estatus de cacique y ejercía un amplio control sobre los p'urhépecha, quienes lo acusaron de realizar aumentos desmesurados en las cuotas tributarias, de robar dinero de los fondos comunitarios y de amenazar a quienes se quejaban, entre otros cargos. El caso constituye una interesante ventana hacia la organización interna de un pueblo de indios, especialmente en cuanto al cobro de tributos, la relación entre principales y macehuales, así como la administración de justicia. La traducción del texto en idioma nativo, que constituye la base del presente artículo, está incluida en un apéndice.

(Michoacán, época colonial, repúblicas de indios, fuentes indígenas, tributos, justicia)

\section{INTRODUCCIÓN}

1 estudio de los textos coloniales en lengua tarasca se ha enfocado sobre todo en la vasta producción de los religiosos franciscanos y de miembros de otras órdenes que escribieron gramáticas, diccionarios, doctrinas cristianas y libros de sermones (entre otras) que sirvieron como importantes instrumentos de

* (roskamp@colmich.edu.mx) (cmonzon@colmich.edu.mx) 
aprendizaje y evangelización. ${ }^{1}$ Mediante la enseñanza en colegios, conventos y hospitales, el arte de la escritura y lectura en alfabeto latino gradualmente se difundió entre la nobleza nativa que fungió como intermediario entre la población indígena y las autoridades espańolas, tanto civiles como religiosas. Aunque el impacto preciso de la alfabetización frecuentemente fue exagerado, sobre todo por los propios doctrineros, es innegable que el proceso educativo rápidamente rindió frutos positivos, como consta en la existencia de un corpus de manuscritos coloniales que fueron redactados por escribanos tarascos o carariecha. ${ }^{2}$ En términos generales, estos especialistas fueron empleados como miembros de los cabildos de pueblos de indios, hospitales y cofradías, pero también como escribanos reales. $\mathrm{Su}$ producción revela una amplia gama de temáticas (herencias, tributos, tierras, abusos de poder, etcétera) y proporciona información indispensable para el mejor entendimiento de la sociedad novohispana y de la compleja interacción entre los diversos grupos de pobladores. ${ }^{3}$

${ }^{1}$ Un panorama general puede encontrarse en: Benedict Warren, "Los estudios lingüísticos en Michoacán en el siglo xvi: una expresión del humanismo cristiano", en Carlos Herrejón Peredo, ed., Humanismo y ciencia en la formación de México, El Colegio de Michoacán, Conacyt, 1984, 113-130; J. Benedict Warren, "Writing the language of Michoacan: sixteenth century Franciscan Linguistics”, en Francisco Morales, ed., Franciscan presence in the Americas, Potomac, Academy of American Franciscan History, 1985, 308344; Ricardo León Alanís, "Los estudios lingüísticos y etnográficos de los religiosos en Michoacán, siglos XvI y Xvıı”, en Carlos Paredes, coord., Lengua y etnohistoria purépecha, Morelia, Universidad Michoacana de San Nicolás de Hidalgo, 1997, 163-178.

${ }^{2}$ Para una presentación de la enseñanza de la escritura y su difusión véase Cristina Monzón, "La semilla misionera; una historia de la grafía en documentos de amanuenses tarascos durante el siglo xvı", en Martina Schrader-Kniffki y Laura Morgenthaler García, eds., Romania en interacción: Entre historia, contacto y politica. Ensayos en homenaje a Klaus Zimmermann, Lengua y Sociedad en el Mundo Hispánico, 18, Frankfurt y Madrid, Vervuert, Iberoamericana, 2007, 179-903.

${ }^{3}$ Véanse los siguientes estudios de caso (entro otros): Cristina Monzón y Hans Roskamp, "El testamento de dońa Ana Ramírez de Acuitzio, Michoacán, 1637", en Relaciones. Estudios de Historia y Sociedad, núm. 86, 2001, 187-207; J. Benedict Warren y Cristina Monzón, "Carta de los principales de Pátzcuaro al obispo Vasco de Quiroga. 10 de marzo de 1549”, en Relaciones., Estudios de Historia y Sociedad, núm. 99, vol. xxv, 2004, 177-211; Frida Villavicencio, "Concierto y carta de venta de tierras y casas. Don Antonio Huithsimengari”, en Tlalocan, vol. xIv, 2004, 27-58; Cristina Monzón, Hans Roskamp y J. Benedict Warren, "La memoria de don Melchor Caltzin (1543): historia y legitimación en Tzintzuntzan, Michoacán”, en Estudios de Historia Novohispana, Universidad Nacional Autónomo de México, 2009, vol. 40, 21-55. 
En esta ocasión presentaremos un documento que fue redactado en 1563 por el escribano del pueblo de indios de Santa Ana Tzirosto, ubicado en Michoacán. El manuscrito en idioma tarasco se encuentra insertado en un expediente del antiguo archivo de la alcaldía mayor de Pátzcuaro, el cual contiene los procedimientos de dos juicios de residencia que se realizaron al gobernador de Tzirosto, uno en 1560 y el otro en 1564, ambos redactados en espańol. ${ }^{4} \mathrm{El}$ texto en lengua nativa destaca por permitirnos realizar una mirada al funcionamiento interior de una república de indios, con especial énfasis en la administración de justicia y el manejo de las cuotas tributarias en San Francisco Corupo, uno de los barrios. Antes de llegar a este nivel micro, proporcionaremos la necesaria visión panorámica del desarrollo histórico previo de Tzirosto como encomienda y pueblo de indios, especificando sobre todo los momentos claves en la legislación tributaria y el gobierno local. Después de la contextualización histórica, la lectura interpretativa y la bibliografía, en el apéndice se incluye la traducción al espańol del propio documento tarasco, cuya extensión considerable nos obligó a presentar su transcripción y análisis lingüístico en una publicación aparte. ${ }^{5}$

\section{La encomienda de Tzirosto}

Al momento de la llegada de los españoles a tierras michoacanas, en 1521, Tzirosto formaba parte del vasto reino tarasco cuya capital era Tzintzuntzan. Según Antonio de Caravajal, quien entre el 22 y 24 de diciembre de 1523 hizo un inventario incompleto de las po-

${ }^{4}$ Archivo Histórico de la Ciudad de Pátzcuaro (AHCP), Caja 131, Legajo 3 (SP112), Año 1564, sin números de fojas. La existencia del expediente con el documento tarasco se encuentra mencionada en Rodrigo Martínez Baracs y Lydia Espinosa Morales, La vida michoacana en el siglo XVI: catálogo de los documentos del siglo XVI del Archivo Histórico de la Ciudad de Pátzcuaro, Colección Fuentes, Instituto Nacional de Antropología e Historia, 1999, 74 .

${ }^{5}$ Este trabajo fue presentado en el seminario interdisciplinario "Pasado y presente cultural de los pueblos indígenas en México" (IIH-UMSNH), en sesión celebrada el 10 de septiembre de 2010. Agradecemos a los organizadores y a todos los participantes por la fructífera discusión, especialmente al Dr. Carlos Paredes Martínez (Ciesas) quien fungió como comentarista oficial y cuyas atinadas observaciones ayudaron a mejorar el texto. 
blaciones en el sur de la sierra, el pueblo pertenecía a la cabecera de Uruapan y era conocido como Chirusto. Tenía con una extensa población, un gobernante propio que se llamaba Antayo y un asentamiento sujeto llamado Chirapan (probablemente Charapan). ${ }^{6}$ El número de lugares dependientes (y por ende también de habitantes) seguramente era mayor pero simplemente no fue registrado, en parte debido a los intereses particulares de los gobernantes en ocultar las dimensiones reales de sus dominios. Cabe agregar que a principios de la década de 1540, Tzirosto (escrito como Xirosto) tenía 4 subcabeceras y un total de 14 barrios, si bien no contamos con una lista de la misma época para llegar a su identificación exacta. $^{7}$

La información recopilada por Caravajal sirvió de base para la adjudicación de las encomiendas a los conquistadores que durante la mayor parte del siglo Xvi tuvieron un papel predominante en la vida política, económica y religiosa del territorio colonial. El 25 de agosto de 1524, Uruapan y sus pueblos sujetos, entre los cuales figuraba Tzirosto, fueron encomendados a Francisco de Villegas. ${ }^{8}$ Mientras que las primeras tasaciones tributarias de la encomienda solamente abarcaban la entrega de diversos alimentos nativos (maíz, ají y frijol), ${ }^{9}$ hacia 1543 las cuotas oficiales eran más diversificadas y también incluían el pago en unidades monetarias (pesos de tepuzque o plata), mantas de algodón, trigo, sal, gallinas, guajolotes y trabajadores para el servicio personal. Además, los indígenas tenían la obligación de proporcionar determinados víveres (gallinas, maíz, hierbas) y leña al calpisque, el encargado del encomendero -probablemente de origen indígena- que residía en Uruapan para cobrar

${ }^{6}$ Las cuentas realizadas por los propios indígenas eran de 30 casas para Uruapan y 40 para Tzirosto, cantidades que el visitador modificó en 150 y 60 respectivamente. Benedict Warren, La conquista de Michoacán, 1521-1530, Morelia, Fimax Publicistas, Colección Estudios Michoacanos, vI, apéndice IV, 1989, 394.

7 "Suma de visitas de pueblos", publicado en Francisco del Paso y Troncoso, Papeles de Nueva España, Segunda Serie, Madrid, Sucesores de Rivadeneyra, , tomo I, 1905, 122 y 310 .

${ }^{8}$ Warren, La conquista..., p.135.

${ }^{9}$ Véase la tasación de Juan de Ortega, de 1528. Warren, La conquista..., pp. 245 y 420. 
y administrar los tributos. ${ }^{10}$ Estos productos también se entregaban al propio Villegas o a sus hijos cuando éstos se encontraban de visita en el pueblo. ${ }^{11}$

En la misma década de 1540, la Corona tomó varias medidas drásticas para controlar a los encomenderos, regular las cuotas tributarias y promover el acceso más generalizado a la fuerza de trabajo indígena. Según las Leyes Nuevas de 1542-1543, las tasaciones tenían que partir de las capacidades reales de la población nativa, estar plasmadas en un documento con copia para las partes involucradas y además debían contar con la aprobación de las autoridades virreinales. ${ }^{12} \mathrm{El} 22$ de febrero de 1549 , se prohibió el servicio personal como parte de los pagos tributarios que de allí en adelante sólo podían consistir en especies y dinero. ${ }^{13}$ En la misma época se empezó a implementar el sistema del repartimiento, mediante el cual los indígenas prestaban servicios remunerados pero forzados-especificados en tasaciones especiales- a todos los pobladores españoles que requerían y solicitaban sus labores. ${ }^{14}$ En la década de 1550, la Corona también empezó a regular la tributación al interior de los pueblos donde las cuotas impuestas por los principales generalmente eran consideradas excesivas y generaban fuertes descontentos entre los macehualtin (macehuales) o p'urhépecha (su equivalente en lengua tarasca). ${ }^{15}$ Los ingresos de estas autoridades locales provenían básicamente de las

${ }^{10}$ Calpisque es la forma hispanizada del término nahua calpixqui, literalmente "el que guarda las cosas de la casa”, aunque en la época colonial generalmente era traducido como "mayordomo". Frances Karttunen, An Analytical Dictionary of Nahuatl, Norman y Londres, University of Oklahoma, 1992, 22.

11 "Suma de visitas...", pp.122 y 310; El libro de las tasaciones de pueblos de la Nueva España, siglo XVI, Prólogo de Francisco González de Cossío, México, Archivo General de la Nación, 1952, 210-212.

${ }^{12}$ José Miranda, El tributo indigena en la Nueva España durante el siglo XVI, México, El Colegio de México, 1952, 99.

${ }^{13}$ Ibidem, pp.103-104.

${ }^{14}$ Bernardo García Martínez, "Trabajo y tributo en los siglos XVI y XVII”, en Gran historia de México ilustrada, México, Editorial Planeta, Consejo Nacional para la Cultura y las Artes, Instituto Nacional de Antropología e Historia, vol. II, 2001, 71.

${ }^{15}$ Para una extensa discusión sobre este término tarasco, véase Pedro Márquez Joaquín, ¿Tarascos o p’urhépecha? Voces sobre antiguas y nuevas discusiones en torno al gentilicio michoacano, Morelia, Universidad Michoacana de San Nicolás de Hidalgo, El Colegio de Michoacán, Morevallado, 2007. 
demasías o sobras de tributos, es decir la diferencia que existía entre las cantidades recaudadas entre sus súbditos y las cuotas que finalmente se tenían que pagar a los encomenderos y a los corregidores (estos últimos eran administradores de la Corona). Para evitar mayores problemas, se establecían tasaciones fijas que tenían que ser obedecidas por todas las partes involucradas. ${ }^{16}$

En los años 1560, a raíz de las visitas del oidor Vasco de Puga y sobre todo del licenciado Jerónimo de Valderrama, el sistema tributario experimentó un cambio fundamental cuando se inició la implementación del cobro fijo per capita: cada tributario tenía que pagar un peso y media fanega de maíz por año, implicando que la carga total dependía directamente de las fluctuaciones demográficas. ${ }^{17} \mathrm{Al}$ mismo tiempo, el padrón de tributarios fue ampliado, al incluir a numerosos principales y gran cantidad de mayeques o terrazgueros que laboraban en tierras de los señores indígenas y que por lo tanto antes no tributaban a la Corona ni a los encomenderos. Obviamente este sistema era provechoso para los españoles porque permitía una recaudación más eficiente y elevada. Sin embargo, su implementación afectó severamente los intereses de la nobleza indígena y tampoco puede perderse de vista que el aumento del total de los pagos tributarios era considerable, en algunos casos incluso implicaba una duplicación en comparación con la situación anterior. ${ }^{18}$

${ }^{16}$ Margarita Menegus Bornemann, Del señorio indígena a la república de indios: El caso de Toluca, 1500-1600, México, Consejo Nacional para la Cultura y las Artes, 1994, 107-111.

${ }^{17}$ Miranda, El tributo indígena..., pp. 169 y 175.

${ }^{18}$ Menegus Bornemann, Del señorío indígena..., pp. 112-138; Rodrigo Martínez Baracs, Caminos cruzados: Fray Maturino Gilberti en Perivan, Zamora, El Colegio de Michoacán, Instituto Nacional de Antropología e Historia, 2005, 53-55. Para estudios detallados sobre la tributación en las encomiendas michoacanas de Juan Infante y Gonzalo Ruiz, véanse los siguientes trabajos: Carlos Paredes Martínez, "El tributo indígena en la región del lago de Pátzcuaro" en Carlos Paredes Martínez et al., Michoacán en el siglo XVI, Colección Estudios Michoacanos, VII, Morelia, Fimax Publicistas, 1984; Hans Roskamp, Los códices de Cutzio y Huetamo: encomienda y tributo en la Tierra Caliente de Michoacán, siglo XVI, Zamora, El Colegio de Michoacán, El Colegio Mexiquense, 2003. 


\section{El PUEBLO DE INDIOS}

Francisco de Villegas al parecer falleció alrededor de 1552 y la gran encomienda quedó dividida entre sus hijos Pedro y Francisco que se quedaron con Uruapan y Tzirosto respectivamente, a pesar de que su primogénito Manuel reclamaba la herencia completa. ${ }^{19}$ En el gobierno indígena, Tzirosto ya se había independizado de la antigua jurisdicción de Uruapan desde antes de $1543 .{ }^{20}$ En este año ambos pueblos tenían la misma carga tributaria y contaban con una extensión demográfica considerable. En el caso de Uruapan se reportaban 430 casas con 2,189 personas, sin contar a los niños. Para Tzirosto primero se calculaban 443 casas y una población total de 1,065 personas, pero también se manejaba la alta cifra de 1,007 casas en que residían 1,664 hombres, 1,906 mujeres y 1,724 niños (es decir 5,294 personas). ${ }^{21}$ Si estos últimos datos fueran los correctos, implicaría que Tzirosto incluso tenía más habitantes que Uruapan, situación aparentemente confirmada para 1570 (aproximadamente) cuando el primero tenía 2,500 y el segundo 1,700 tributarios. ${ }^{22}$ Su importancia no sólo consta por el tamaño demográfico y cuota tributaria sino también por el hecho de que hacia el mismo año de 1570 llegó a funcionar como cabecera de curato con los siguientes 18 barrios: San Pedro Tzacan, Santiago Parangaricotiro, San Josefe, Cingauan [Angahuan], Santa Catalina, Quanbocheo, Hapo, San Josefe, San Francisco [Corupo], Nurio, Charapan, Hapo, Tepachao, Santángel

${ }^{19}$ Carlos Paredes Martínez, ed., et al., Y por mí visto...Mandamientos, ordenanzas, $l i$ cencias y otras disposiciones virreinales sobre Michoacán en el siglo XVI, México, Centro de Investigaciones y Estudios Superiores en Antropología Social, Universidad Michoacana de San Nicolás de Hidalgo, 1994, 120-121. Véase también el Archivo General de Indias, Patronato, 278, N. 2, R. 216, fecha 11-04-1540.

${ }^{20}$ Conviene tener en cuenta que la única indicación de que Uruapan fue su cabecera, viene de la temprana y problemática visita de Caravajal (1523). Por lo tanto, no se puede descartar que Tzirosto ya haya sido autónomo al momento de la llegada de los espańoles, sobre todo porque no hemos encontrado ninguna información sobre su posible separación, proceso que por lo regular generaba muchos conflictos.

${ }^{21}$ Véase El libro de las tasaciones..., p. 210; "Suma de visitas...", pp. 122 y 310.

${ }^{22}$ Luis García Pimentel, Relación de los obispados de Tlaxcala, Michoacán, Oaxaca y otros lugares en el siglo XVI. Manuscrito de la colección del señor Don Joaquin García Icazbalceta, en casa del editor, México, 1904, 155. 


\section{[Zurumucapio], Santiago Tingambato, Curundahpan, Curu [San} Andrés Coru] y Taretan. Cabe agregar que varios de estos asentamientos estaban ubicados muy cerca de Uruapan pero a una considerable distancia del propio Tzirosto. ${ }^{23} \mathrm{~A}$ pesar de la falta de información, es probable que para la erección del curato, las autoridades religiosas hayan seguido - por lo menos a grandes líneas- la estructura y extensión del propio pueblo de indios. En este sentido no sería coincidencia que el número de barrios en 1568 (18) sea igual a la cantidad de sujetos (4 subcabeceras y 14 sujetos) en $1543 . .^{24}$

En las décadas de 1550 y 1560, igual que en otras localidades de la misma región, Tzirosto debe haber consolidado su propio cabildo, una forma organizacional de las autoridades de los pueblos de indios que fue impuesta por los espańoles pero que también incorporaba varios elementos nativos. ${ }^{25}$ Este órgano, cuyos miembros se elegían de manera anual, era presidido por el gobernador quien constituía el principal intermediario entre los indígenas del pueblo y sus vecinos, las autoridades españolas y los religiosos. Entre sus obligaciones y facultades estaban la ejecución de órdenes reales y virreinales, la recaudación y entrega puntual de los tributos, la organización de las tandas para el servicio personal, la colaboración en la implementación efectiva de la doctrina cristiana, así como la administración de justicia en el caso de delitos menores y del orden pú-

${ }^{23}$ En la lista de 18 nombres, hay dos que están repetidos: San Josefe y Hapo. El último también aparece como barrio del curato vecino de Tancítaro. Nurío está reportado como perteneciente a Aranza, igualmente colindante con Tzirosto. Ibidem, pp. 36-38. Este último dato coincide con las investigaciones que se han realizado sobre la encomienda de Juan Infante, a la que pertenecían tanto Aranza como Nurío. Véase Paredes Martínez, "El tributo indígena en la región...", p. 53.

${ }^{24}$ En la década de 1570, la administración religiosa llegó a manos de los agustinos quienes fundaron conventos en Tzirosto, San Felipe de los Herreros, Zacan, Parangaricutiro y Tingambato. ¿Acaso estos últimos cuatro eran las subcabeceras mencionadas en 1543? Ricardo León Alanís, Los orígenes del clero y la Iglesia en Michoacán, 1525-1640, México, Universidad Michoacana de San Nicolás de Hidalgo, Instituto de Investigaciones Históricas, 1997, 80.

${ }^{25}$ Carlos Paredes Martínez, "Gobierno y pueblos de indios en Michoacán en el siglo Xvi” en Carlos Paredes Martínez, director general, Arquitectura y espacio social en poblaciones purépechas de la época colonial, Morelia, Universidad Michoacana de San Nicolás de Hidalgo, Universidad Keio, Centro de Investigaciones y Estudios Superiores en Antropología Social, 1998, 21-45. 
blico. En este último rubro contaba con la asistencia de dos o más alcaldes ordinarios y un alguacil mayor. Los alcaldes incluso fungían como jueces en los casos que no ameritaban la intervención del gobernador. Como consejeros generales se disponía de un grupo de regidores que representaban a los sujetos y barrios, subdivisiones del pueblo de indios que también contaban con sus propios alcaldes y alguacil. En el cabildo también había un mayordomo que administraba los bienes del pueblo y un escribano que se encargaba de leer, redactar y archivar toda la correspondencia.

Otros oficiales eran los uhcambecha (ocambecha), los mandones que se encargaban en primera instancia de la recolección de tributos, el levantamiento de los padrones de tributarios y la organización del servicio personal. Eran asignados a la cabecera y a cada uno de los sujetos, aunque su número preciso también variaba de acuerdo a la cantidad de tributarios. ${ }^{26}$ Estos oficiales ya existían en la época prehispánica, cuando cumplían básicamente las mismas funciones en la administración del reino tarasco. ${ }^{27}$ El término uhcambeti (plural uhcambecha), que en los diccionarios de la época colonial es interpretado simplemente como mandón o capitán, pone énfasis en el ir o estar con alguien sin tomar parte en la actividad, resaltando que las personas acompañadas ocupan una posición social inferior. Por lo tanto su traducción literal sería "el que acompaña sin participar". ${ }^{28}$

${ }^{26}$ Felipe Castro Gutiérrez, Los tarascos y el imperio español. 1600-1740, México, Universidad Nacional Autónoma de México, Universidad Michoacana de San Nicolás de Hidalgo, 2005, 121-129.

${ }^{27}$ Jerónimo de Alcalá, Relación de las cerimonias y rictos y población y gobernación de los indios de la provincia de Mechuacán, Moisés Franco Mendoza, coordinador de edición y estudios, Zamora, El Colegio de Michoacán, Gobierno del Estado de Michoacán, 2000,528 y 559.

${ }^{28}$ Este análisis parte de la siguiente combinación morfológica. La raíz 'vhca' se interpreta como 'tener' y cuando se predica de personas, se entiende que éstas se encuentran supeditadas al agente, como por ejemplo en 'vhcahpeni' o 'tener criados, siervos y moços'. El sufijo 'mbe' indica que el agente posee una característica intrínseca positiva, lo que se puede apreciar en el siguiente contraste: 'exeni' o 'ver, mirar' y 'exembeni' o 'alegrarse de verlo'. De lo anterior se puede interpretar la concatenación 'vhcambe' con el significado literal de 'tener en forma positiva a una o varias personas', atenuándose la idea de supeditación observada en 'vhcahpeni' sin que esta misma desaparezca, como se puede apreciar en las traducciones dadas a uhcambeti: 'Vhcambeti...Mandon', así como 'Capitanear alguna poca jente...vhcambeti etspeni, vhcambeti eni'. En traducción libre tene- 
Cabe agregar que en lengua náhuatl se empleaba la palabra tequitlato, "el repartidor del tributo/distribuidor del trabajo". ${ }^{29}$

Además de los anteriores cargos oficiales, cuya conformación y número exacto podía variar de acuerdo al tamaño y estatus del pueblo en cuestión, también había otras personas con considerable injerencia en la vida interna de los asentamientos. En este sentido conviene mencionar a los ancianos o tharepecha y los oficiales del hospital, institución sociorreligiosa de suma importancia en el área tarasca que estaba directamente relacionada con el gobierno local y la administración de los bienes del pueblo de indios y de todas sus parcialidades. $^{30}$

A pesar de que muchos asuntos deben haberse resuelto de manera oral, las cuestiones de mayor importancia al interior del pueblo de indios - especialmente las cuentas tributarias y tasaciones de servicio personal- se tenían que registrar en libros de cabildo. Todos los documentos se guardaban en una caja de tres llaves o caja de comunidad (que no necesariamente era un cofre pues también podía ser un cuarto o troje con cerrojos), misma que también contenía las aportaciones tributarias en dinero y en especie de todos los contribuyentes indígenas. El control sobre las aportaciones y la documentación estaba asegurado, por lo menos de manera teórica, por el hecho de que solamente era posible acceder a ellas mediante el conjunto de tres llaves, las cuales eran distribuidas al gobernador, ma-

mos 'vhcambehpeni' o 'estar en compañia o acompañando'. Nótese además que en la oración 'vhcambeni ahchuhcharihpeni' o 'traerlos o tenerlos perseguidos', la persona que acompańa -al traerlos o tenerlos- no participa de la persecución. Véase el Diccionario grande de la lengua de Michoacan, por autor o autores desconocidos, introducción, paleografía y notas por J. Benedict Warren, 2 tomos, Colección "Fuentes de la Lengua Tarasca o Purépecha” v, Morelia, Fimax, 1991. Según Seler uhcambecha quiere decir 'tener gente junto', estableciendo una relación con el término 'hucamani' -según él intercambiable con 'uhcamani'- o 'los que tienen junto a sí un número mayor de cosas'. Véase Eduard Seler, "Los antiguos habitantes de Michoacán", en Alcalá, Relación de las cerimonias..., p. 201.

${ }^{29}$ Rémi Siméon, Diccionario de la lengua náhuatl o mexicana redactado según los documentos impresos y manuscritos más auténticos y precedido de una introducción, México, Siglo XXI, 1994, 512.

${ }^{30}$ Castro Gutiérrez, Los tarascos..., pp. 130-131; Paredes Martínez, "Gobierno y pueblos...", pp. 34-35. 
yordomo y alcalde. No sólo las cuotas tributarias salían de la caja de comunidad sino también los diversos gastos generales en beneficio del pueblo e incluso el salario fijo de los propios oficiales del cabildo y otras autoridades locales quienes eran pagados con las demasías de los tributos. ${ }^{31}$ En 1565, por ejemplo, el pueblo de indios de Uruapan juntó 2,004 pesos y 4 tomines de oro, así como 844 fanegas de maíz, de los cuales el encomendero Pedro de Villegas recibía el maíz y 1,688 pesos, quedando el resto (316 pesos) para los gastos del pueblo. ${ }^{32}$ La remuneración exacta de las autoridades locales, autorizada por el virrey en turno, al parecer variaba de acuerdo al estatus político y económico del pueblo en cuestión.

Si bien, en la historiografía tradicional se han enfatizado los abusos cometidos por el régimen colonial y sus representantes españoles, la documentación disponible muestra que la vida al interior de los pueblos de indios de ninguna manera era idílica y libre de conflictos. Además del continuo faccionalismo en las elecciones anuales de las autoridades locales, también pueden mencionarse los múltiples abusos de poder por parte de los oficiales. Los casos más llamativos por lo general nos remiten a los excesos cometidos por el gobernador cuyo cargo le daba muchas oportunidades de beneficiarse más allá de sus atribuciones y remuneraciones autorizadas: entre la amplia gama de quejas es común encontrar las que se remiten a diversos tipos de fraude en la recaudación de los tributos y administración de los servicios personales. ${ }^{33}$ Como cualquier otro oficial público, los gobernadores tenían la obligación de rendir cuentas al final de su administración o cuando la Corona se lo pidiera, por ejemplo, en los casos en que existían sospechas o indicaciones concretas de malversaciones. La máxima autoridad local era sometida a un juicio de residencia, lo que implicaba que un juez visitador hiciera una revisión de su gestión, teniendo en cuenta, tanto documentación del cabildo, como testimonios orales.

${ }^{31}$ El libro de las tasaciones..., pp. 212-213; Paredes Martínez, "Gobierno y pueblos...", pp. 36-39.

${ }^{32}$ Oziel Ulises Talavera Ibarra, Historia del pueblo de indios de San Francisco Uruapan, Morelia, Morevallado Editores, 2008, 44-45; El libro de las tasaciones..., pp. 212-213.

${ }^{33}$ Castro Gutiérrez, Los tarascos..., pp. 120-125. 


\section{LA VISITA DE I 560}

Hacia finales de la década de 1550, el virrey Luis de Velasco ordenó que se investigara el manejo de las sobras de tributos por parte del gobernador, principales y mayordomos de Tzirosto. ${ }^{34} \mathrm{El}$ alcalde mayor de Michoacán, Alonso Corrales, fue comisionado a realizar un juicio de residencia y el 22 de marzo de 1560 visitó el pueblo donde, en presencia de las mencionadas autoridades locales, mandó llamar al escribano para que presentara los libros de cabildo con las cuentas correspondientes al manejo de los tributos. El oficial inmediatamente señaló que la información estaba incompleta y que no se mencionaban sobras de tributos sino sólo algunos gastos para sueldos de alcaldes y procedimientos jurídicos. Por lo tanto, decidió realizar su propio cálculo aproximado de los excedentes y para tal efecto mandó que los principales contaran a todos los habitantes indígenas de la cabecera y de cada apatzequa (barrio/sujeto), incluyendo a viudos, viudas e incluso a la gente libre de tributación. De esta manera se llegó a un total de 1,735 personas, de las cuales 363 originalmente estaban reservadas por pertenecer a la nobleza local. ${ }^{35}$ A partir de esta cifra el alcalde ordenó que de allí en adelante todos pagaran tributos, con excepción de los principales antiguos o "de casta”, cuyo número ascendía a dos por cada sujeto y una cantidad desconocida en la cabecera. También quedaron exentas las personas (cuyo número no se especifica) que prestaban sus servicios en la iglesia. En cuanto a los 418 ancianos del pueblo, determinó que 18 no tenían la capacidad de tributar, agregando que los demás contribuyeran con dos tomines al año. La tasación para los casados, así como de cada combinación de viudo y viuda (contabilizándolos como si formaran parejas o familias nucleares), era de 6 tomines. A esto habría que sumar el conjunto de 200 fanegas de maíz que te-

${ }^{34}$ AHCP, Caja 131, Legajo 3 (SP112), Año 1564, sin números de fojas.

${ }^{35} \mathrm{Si}$ comparamos estas cifras de 1560 con los datos disponibles para el ańo 1570, la década intermedia se caracteriza por un aumento considerable de tributarios (de 1,735 a 2,500 ). Aunque una de las causas pudo haber sido la fluctuación general de la población (migraciones y congregaciones), hay que pensar sobre todo en la ya mencionada redefinición de los tributarios que llevó al empadronamiento de muchos principales y terrazgueros. 
nían que ser aportadas únicamente por los matrimonios. De esta manera se llegó a determinar una capacidad tributaria en moneda de 1,378 pesos, 6 tomines de oro y el maíz. ${ }^{36}$ Teniendo en cuenta que la cuota tributaria para el encomendero era de 800 pesos y 200 fanegas de maíz, las sobras se calcularon en 578 pesos y 6 tomines, de donde podían pagarse el sueldo del sacerdote y los demás gastos en beneficio de la comunidad, que incluían los pagos para los integrantes del cabildo. ${ }^{37}$ Este remanente tenía que guardarse en la caja de comunidad, con sus respectivas llaves para el gobernador, alcalde y mayordomo, anotándose todos los movimientos en un libro encuadernado y organizado en capítulos, para que de allí en adelante existiera claridad sobre las finanzas.

Junto con la ampliación del padrón y el establecimiento de cuotas fijas per capita, que según los cálculos del alcalde debería llevar a una mayor recaudación y un incremento en los fondos para la comunidad, también se llegaron a determinar los sueldos para algunos de los oficiales del cabildo. Al gobernador don Pedro Cutao, quien se quejaba de que sus ingresos no le alcanzaban, le autorizaron un aumento de 10 pesos al ańo, para llegar al total de 20 pesos que eran acompañados por los beneficios de unas sementeras de maíz. A los alcaldes se les otorgaba la cantidad de 5 pesos, especificando que serían desterrados en caso de que pidieran más. Al mismo tiempo se nombraron 4 regidores con una remuneración anual de 3 pesos

${ }^{36}$ Nuestros propios cálculos a partir de la misma información han producido resultados ligeramente diferentes. Si la recaudación total fuera de 1,378 pesos y 6 tomines, y la parte contribuida por los 400 ancianos llegara a 100 pesos ( 2 tomines por individuo), el restante de 1,278 pesos y 6 tomines correspondería a 1,705 tributarios con una cuota individual de 6 tomines (y no a las 1,735 personas mencionadas en el documento). Lo anterior también implica que los ancianos no están contabilizados en la cifra de los 1,735 y que esta misma cantidad no representa la población total sino únicamente el número de tributarios regulares. Obviamente estas discrepancias y detalles dificultan en gran medida la obtención de una idea clara sobre las fluctuaciones de pobladores y tributarios.

${ }^{37}$ Según una relación de los pueblos de indios novohispanos que estaban en encomienda, realizada en enero de 1560 , los tributos de Tzirosto (dinero y maíz) representaban un valor de 870 pesos, la misma cantidad que se reportaba en el caso de Uruapan. Cabe agregar-como señalamos anteriormente- que ya hacia 1543 ambos pueblos tenían la misma tasación tributaria. Francisco del Paso y Troncoso, Epistolario de Nueva España 1505-1818, tomo Ix (1560-1563), México, Antigua Librería Robredo, 1940, 16 y 30. 
(Diego Cahupa, Alonso Carocome, Pedro Herondase y Joan Arandico) para que se encargaran de juntar los tributos y de meterlos a la caja de comunidad con las tres llaves. Estos oficiales debían impedir que terceros interfirieran en la tributación y sobre todo tenían que fijarse en los muchos principales autonombrados -que no pertenecían a las antiguas familias o linajes de nobles- que de allí en adelante estaban obligados a tributar y que de acuerdo al alcalde antes solamente robaban a los naturales. El 3 de abril de 1560, las medidas tomadas por Alonso Corrales fueron ratificadas por el virrey.

Aunque en la información disponible solamente se mencionan las acciones del alcalde mayor, queda claro que el origen de su visita probablemente deba buscarse en una denuncia por parte de los p'urhépecha sobre los manejos poco transparentes de las sobras de tributos por parte del gobernador y el resto del cabildo, aunado a una serie de obligaciones adicionales impuestas por parte de las autoridades y principales del lugar. Estas tensiones entre los macehuales y sus seńores se ubican en el contexto más amplio de los intentos, por parte de la Corona, de ejercer un mayor control sobre los gobernantes indígenas, no sólo para evitar abusos en perjuicio de sus súbditos, sino sobre todo con el fin de mejorar la recaudación general de tributos y hacer un uso más eficiente y benéfico (para los españoles) de la fuerza de trabajo nativa. Como señalamos arriba, unas de las medidas que se tomaron fueron el cobro por individuo y la ampliación del padrón de tributarios. Aunadas a la determinación de ingresos fijos para las autoridades locales, ambas fueron implementadas en Tzirosto precisamente cuando ya existía descontento entre los p'urhépecha sobre la administración por parte de sus principales, una táctica oficial que incluso figura en las instrucciones que el virrey Antonio de Mendoza dejó a su sucesor Velasco, en abril de $1550 .{ }^{38}$

\section{EL JUICIO DE RESIDENCIA DE I 564}

A pesar de haber recibido claras instrucciones en cuanto a la administración de la tributación y la caja de la comunidad, en Tzirosto

${ }^{38}$ Menegus Bornemann, Del señorío indigena..., p. 107. 
seguían existiendo malos manejos e incluso se agravaron las tensiones entre los macehuales y los principales, especialmente con el gobernador. Esta situación no era excepcional, como consta del hecho de que en 1561, el virrey Luis de Velasco ordenó que se investigara a todos los caciques y gobernadores de la provincia, dando origen a una serie de juicios de residencia que fueron llevados a cabo en los ańos posteriores. ${ }^{39}$ Entre el 3 y el 11 de julio de 1564, el gobernador don Pedro Cutao de Tzirosto fue sometido a un juicio de residencia por parte del juez Juan de Baeza. ${ }^{40}$ La investigación arrojó 13 acusaciones en contra de la mencionada autoridad local que ya tenía por lo menos 5 años en el cargo: 1) haber quitado 1,336 pesos y 4 tomines de oro común a los tributarios sin tasación ni autorización; 2) la recepción de 190 pesos de oro común del padre Francisco de la Çerda para la construcción de una casa de los franciscanos en la Ciudad de Michoacán, sin pagar a los trabajadores indígenas; 3) la omisión del pago a los naturales que le hicieron unas casas en el pueblo, a sabiendas de que esta actividad no estaba prevista en la tasación tributaria; 4) ser mal ejemplo para los indígenas al emborracharse con vino de la tierra y de Castilla; 5) exigir a los terrazgueros que le tenían que trabajar una sementera de maíz de 20 brazas en el cuadrado mientras que su tasación decía que sólo era de 14 de largo y poco más de uno de ancho; 6) no haber entregado el dinero a los naturales que construyeron unas casas en la estancia de Pedro de Silva; 7) no dar el buen ejemplo y ofender a Dios por estar amancebado con dos mujeres casadas del pueblo de Parangaricutiro; 8) amenazar al hombre que reclamó a su esposa infiel en presencia del gobernador; 9) el maltrato y abuso en contra de las indias que trabajaban en su casa, conforme a la tasación vigente; 10) exigir como sueldo anual el doble de los 10 pesos de oro que estaban autorizados en la tasación, junto con los frutos del trabajo en unas sementeras; 11) no haber

${ }^{39}$ Martínez Baracs, Caminos cruzados..., pp. 56-58; Castro Gutiérrez, Los tarascos..., p. 124 .

${ }^{40}$ AHCP, Caja 131, Legajo 3 (SP112), Año 1564, fojas sin numeración. Baeza tenía amplia experiencia como intérprete jurado de la lengua tarasca, alguacil de la Ciudad de Michoacán (Pátzcuaro) y corregidor del pueblo de Chilchota. Martínez Baracs, Caminos cruzados..., p. 59. 
administrado justicia a los indios de San Francisco que vinieron a quejarse sobre su cacique Cristóbal quien había cometido robos y malos tratos; 12) volver a amancebarse con una india llamada María después de que el virrey lo había castigado por este hecho en la Ciudad de Michoacán; 13) la retención de 80 pesos de oro común que el pueblo vecino de Periban había tenido que pagar a Tzirosto por la invasión de unas tierras en Tepachao Amocutin. ${ }^{41}$

Teniendo en cuenta que el análisis completo del interesante juicio será tema de un estudio aparte, quisiéramos enfocarnos aquí en el onceavo cargo que trata de la aplicación de la justicia, una de las principales atribuciones del gobernador. En su defensa, el gobernador confirmaba brevemente que los indígenas de San Francisco se habían presentado ante él para quejarse de robos y maltratos cometidos por su cacique Cristóbal. Aunque la información fue debidamente registrada por los alcaldes, él les dio la instrucción de suspender el juicio para dejar la administración de justicia al juez de residencia (que sabemos era Juan de Baeza) quien estaba por visitar el pueblo. A don Pedro la acusación le parecía carecer de valor porque él había realizado las acciones correspondientes al tomar las declaraciones sobre el caso, previendo la resolución final por parte del juez. Este último al parecer no se dejó impresionar por la explicación y llegó a la conclusión de que el gobernador era quien tenía que haber administrado la justicia en vez de dejar los procedimientos en manos de los alcaldes que no tenían el conocimiento adecuado para resolver el caso.

\section{LOS USOS Y ABUSOS DEL UHCAMBETI}

Aunque no sabemos si las acusaciones en contra del cacique Cristóbal de San Francisco fueron retomadas por Juan de Baeza, el gobernador o algún otro administrador de justicia, sí existe clara evidencia de que uno de los alcaldes de Tzirosto efectivamente tomó noticia de las quejas y llegó a registrar los testimonios de los acusadores y del propio acusado. Esta información, escrita en lengua tarasca y adjun-

${ }^{41}$ Comos señalamos arriba, Tepachao se encuentra en la lista de barrios de Tzirosto (en 1570). 
ta a las escrituras del juicio de residencia de 1564, abre una ventana hacia la organización del pueblo de indios y su administración de justicia, con especial énfasis en la organización tributaria y el funcionamiento del uhcambeti en un asentamiento sujeto a la cabecera. ${ }^{42}$

Un 20 de diciembre, probablemente del año 1563,43 don Alonso Tzintzu, alcalde de Tzirosto, acudió a San Francisco Corupo (en el documento se encuentra escrito como Curupo) para dar seguimiento a unas quejas en contra del uhcambeti o mandón Cristóbal Tzurequi, acusado de robos y otros abusos relacionados con el pago de tributos durante un lapso de dos años. El oficial, acompañado por el escribano Martín Vuapeme, se refería a los presentes como habitantes y p’urhépecha (macehuales), aunque también manejaba el término de miyuparacha o empadronados de Santa Ana Tzirosto, indicando su sujeción y obligaciones hacia la cabecera. ${ }^{44}$ Se dirigía especialmente a Francisco Zintzu, Martín Tena, Juan Evatsi, Bartolomé Tangutsi, Melchor Quaraqui y también a Martín Tangutsi. Tras ser invitados a ampliar la información sobre las acciones de Cristóbal, se presentaron 6 testigos: Diego Tzuraqui, Juan Tzurequi, Pedro Tzutirani, Andrés Cahmahchacu, Alonso Quema, Juan Vanizcume y el propio acusado Cristóbal Tzurequi.

Las seis declaraciones, resumidas en el cuadro 1, coinciden en el número de ocasiones en que el uhcambeti cobró tributos de los habitantes de San Francisco: 6 veces en el primer año y 13 en el segundo. Los montos individuales y sobre todo los totales que se reportan, también muestran grandes similitudes. Sin embargo, sí existen inexactitudes y diferencias entre varios testimonios, probablemente debidas a confusiones en el orden y naturaleza precisos de los dife-

42 AHCP, Caja 131, Legajo 3 (SP112), Año 1564, fojas sin numeración.

${ }^{43}$ Ya vimos que el gobernador don Pedro argumentaba que la aplicación de la justicia en el caso de San Francisco fue pospuesta hasta la llegada del juez visitador en julio de 1564 .

${ }^{44}$ El término 'miyuparacha' (el singular es 'miyuparari') literalmente significa 'aquellos cuya espalda es contada' y está compuesto por la raíz 'miu' cuyo significado es 'contar', el morfema -para que denota la espalda, así como el sufijo -cha para el plural (-ri para singular). Véase el Diccionario Grande... La misma fuente indica que la palabra también fue empleada en un sentido más amplio - por lo menos por parte de los frailes evangelizadores- para referirse a vasallos, comarcanos, pobladores, feligreses y ciudadanos. 
rentes pagos, así como problemas de cálculo en la suma total. Sólo los 2 primeros testigos, Diego Tzuraqui y especialmente Juan Tzurequi, dieron datos incompletos mientras que los siguientes 4 declarantes reportaron información detallada y prácticamente idéntica. En este sentido conviene resaltar la existencia de los mismos errores en la determinación de los tributos subtotales y totales que apuntan a una consulta previa entre los propios testigos o simplemente a la existencia de algún tipo de registro escrito. Las diferencias más grandes se encuentran entre los montos de los diversos cobros reportados por el uhcambeti y los que fueron señalados por los acusadores de San Francisco, si bien debe señalarse que las cuentas totales del oficial local no muestran grandes discrepancias y son solamente un poco más bajas. No obstante, nuestro propio cálculo arroja una suma que sí es mayor a la de los demás declarantes.

Todos los pagos que los p'urhépecha efectuaron directamente al mandón Cristóbal, se realizaron en moneda, con una interesante excepción. Se trata de la entrega de una determinada cantidad de mantas que se usaban como onguequa o falda, elaboradas por las mujeres casadas y las viudas que formaban parejas de dos, cada una de las cuales tenía la obligación de dar una pieza, evaluada en 5 tomines (por lo tanto en el cuadro 1 sólo aparece el equivalente en dinero). ${ }^{45}$ Según el primer testigo, Diego Tzuraqui, esta vestimenta se elaboraba en un lugar conocido como pequaro, ubicado en el hospital de la localidad. Este término tarasco puede traducirse como "lugar de parir" y parece indicar el carácter tanto femenino como

${ }^{45}$ La traducción exacta del término onguequa es problemática. Si partimos de la raíz 'o' para tapar y el morfema de espacio -ngue como pecho, significaría 'algo que tapa el pecho' y quizá podríamos interpretarlo como un tipo de quexquemetl. Compárese con 'Yongueni. Tener largos pechos, o largo cuerpo desde la çintura a la garganta, ser largo de talle', donde la raíz 'yo' remite a 'largo' (véase el Diccionario grande...). Sin embargo, también existe la entrada 'ongueni' que Lagunas interpreta como 'ser concebida la criatura. i. Encerrada, o cubierta, o atajada dentro del hueco de la matriz' y que en el Diccionario grande aparece como 'Conçebir la mujer'. Esta información, confirmada por dos fuentes del siglo XVI y aunada a la expresión tasta onguequa de la deposición del uhcambeti, nos lleva a sugerir la traducción de onguequa como rollo o sea la manta que utilizan las mujeres a manera de falda. Véase Juan Baptista de Lagunas, Arte y dictionario con otras obras en lengua Michuacana, introducción histórica con apéndice documental y preparación fotográfica del texto por J. Benedict Warren, Morelia, Fimax Publicistas Editores, 2002. 
productivo de este espacio específico. ${ }^{46}$ Aunque una parte de las manufacturas servía para cumplir con las cuotas tributarias, es probable que el remanente haya sido comercializado en mercados locales y regionales. Las mantas ocupaban un lugar muy importante en la economía colonial e incluso servían como unidad de intercambio, teniendo en cuenta que la circulación de monedas era reducida.

Como consta en el cuadro 1 y además fue claramente señalado por el cuarto declarante Andrés Cahmahchacu, existe un aumento considerable en el número y monto de los cobros del segundo año: un poco más de una duplicación en cuanto al número de entregas y una triplicación en las cantidades. Además, las partes afectadas alegaban que el uhcambeti sustraía partes del dinero que se había pagado y que era guardado en una vasija, objeto que nos parece estaba funcionando como una pequeña caja de comunidad en el nivel local de San Francisco. Según el segundo testigo, Juan Tzurequi, se daban cuenta de los hechos al momento de hacer el conteo de los contenidos del mencionado recipiente de cerámica. La irregularidad, el incremento y el robo no son las únicas causas de la inconformidad por parte de los tributarios ya que acusan al oficial de otros abusos relacionados (que en el mencionado cuadro constituyen el rubro de los "cobros extras").

Se alegaba que todos los p'urhépecha solían trabajar en las tierras de Alonso Tziquan, Alonso Hinaqua, Juan Vuazcume y posiblemente también de otras personas, servicios que eran pagados, pero cuyo monto no les era entregado sino que quedaba en manos del mandón que al parecer organizaba, controlaba y cobraba este tipo de actividades. Sabemos que en la cabecera de Tzirosto existía la misma dinámica ya que en su visita de 1560, el alcalde mayor Alonso Corrales dio

${ }^{46}$ La raíz 'pe' de esta palabra podría ser la misma que encontramos en "Peuani. Parir a vno.", "Peuahpeni. Parir munchos." (véase el Diccionario grande...). El morfema espacial -ua se refiere al vientre, en estos casos de la mujer que pare. Compárese con "Cuerauanstani. Tornarse a desatar, soltar o librar el vientre de las preńadas". Lagunas, Arte y dictionario... El elemento -hpe refiere a varias personas y -ni es el infinitivo. En el contexto de un lugar, el morfema -ua no puede aparecer puesto que el lugar mismo no tiene vientre. Por lo tanto a la raíz 'pe' se le adjunta el sufijo -qua para formar un sustantivo y se le añade -ro para indicar que se trata de un lugar. 
órdenes para que se tratara y pagara bien a quienes laboraban en casas y tierras ajenas, condiciones que 4 años más tarde no eran cumplidas por el uhcambeti de Corupo. ${ }^{47}$ Cristóbal Tzurequi también era acusado de retener las ganancias de la venta del maíz de la comunidad en Pátzcuaro, así como de quedarse con las sobras del maíz que se tributaba al encomendero Francisco de Villegas. Finalmente, se le imputaba haber regañado a los p'urhépecha y haber castigado a las personas que se habían quejado de sus acciones, imponiéndoles multas en dinero cuyos montos al parecer variaban en cada caso. En este contexto es interesante mencionar que los declarantes Andrés Cahmahchacu, Alonso Quema y Juan Vanizcume comentaban que el uhcambeti advertía a los macehuales querellantes que éstos no se irían a ningún lugar, es decir que no podían escapar de su control. ${ }^{48}$ Todos estos cargos fueron negados por el acusado quien explicaba que no había recibido dinero por multas y que había regresado (probablemente depositándolo en la vasija) el monto de la venta de maíz en Pátzcuaro. Agregó que el dinero de la venta de maíz del año anterior se realizó en San Felipe (de los Herreros) y que una parte se ocupó para comprar sal mientras que el remanente fue llevado a la cabecera Tzirosto por un personaje llamado Gonzalo. En cuanto al pago del trabajo en las sementeras, Cristóbal Tzurequi decía que el señor Domingo se lo había llevado. ${ }^{49}$ Finalmente, negaba haber visto el maíz que supuestamente había sobrado de los tributos para el en-

${ }^{47}$ El primer declarante, Diego Tzuraqui, dijo que una parte de los ingresos para los trabajadores se destinaban al pago del escribano, pero que también era guardada por el mandón, información que no es mencionada en los otros testimonios. Si este dato fuera correcto, podría implicar que el uhcambeti disponía de los servicios de un escribano para el registro de la administración local.

${ }^{48}$ Esta observación del oficial hace pensar en el sistema prehispánico de gobierno indígena que se basaba en las relaciones directas entre las autoridades y sus súbditos. Las obligaciones de los últimos se mantenían aun cuando pretendían cambiar su lugar de residencia (Personenverband). En la época colonial, este sistema fue reemplazado gradualmente por otro que partía más bien de la definición de territorios y jurisdicciones (Territorialverband). Véase Roskamp, Los códices de Cutzio..., pp. 106-107.

${ }^{49}$ El primer testigo, Diego Tzuraqui, mencionó un tal Domingo Tangutsi que también recibió dinero por las labores que los macehuales realizaron en las tierras de diversas personas. No hay información sobre las circunstancias precisas ni sobre la identidad de este personaje que no aparece en los testimonios de los demás querellantes. 
comendero, especificando que él llevó "el pleito por 90 pesos" a la ciudad y preguntando “ ¿acaso cambié algo con el negocio?”, comentarios que nos resultan difíciles de interpretar. ${ }^{50}$

La documentación disponible nos proporciona algunos datos que permiten tener una idea aproximada de la demografía local. Como se mencionan tanto el cobro por persona como el total por casi cada entrega, en la gran mayoría de los casos el cálculo llega a 80 tributarios. ${ }^{51}$ Es importante recalcar que esta cifra no es la población total y sólo representa a las cabezas de familia y -si aplicáramos los criterios del alcalde mayor durante su visita a Tzirosto en 1560también a viudos y ancianos considerados aptos para aportar algunas cuotas. Aunque carecemos de datos sobre la población total y de su composición precisa (adultos, niños, ancianos, etcétera), sí contamos con información que permite reconstruir la cantidad de mujeres casadas y viudas de Corupo. Sabemos que ellas se encargaban de elaborar textiles y conocemos tanto la cuota por cada dos trabajadoras como el total de la producción, lo que permite pensar en un número probable de 50 mujeres. ${ }^{52}$ Teniendo en cuenta que en 1560 ,

${ }^{50}$ Aunque es posible que el remanente del tributo de maíz haya sido motivo de un pleito entre Corupo y el encomendero, no queda clara su naturaleza ni el papel que en ello pudo haber jugado el uhcambeti, sobre todo a sabiendas de que la representación del pueblo y de todos los sujetos generalmente correspondía al gobernador, alcaldes y otras autoridades de la cabecera.

${ }^{51}$ Una primera excepción se encuentra en el testimonio de Diego Tzuraqui quien para el primer ańo habla de dos entregas iniciales de medio tomín por persona y un total de 5 pesos (entonces 40 personas), así como un tercer pago de medio tomín con una suma de 15 pesos (lo que equivaldría a 240 tributantes). Este último coincide con la declaración del uhcambeti Cristóbal Tzurequi. El problema no existe en el caso de los demás declarantes. La segunda excepción se ubica en el cobro número 12 del segundo año donde según Andrés Cahmahchacu les quitaron un tomín por cada grupo de 4 macehuales, llegando a un total de 20 pesos (lo que implicaría la existencia de 640 contribuyentes). De acuerdo a Alonso Quema y Juan Vanizcume la recaudación era efectivamente de 20 pesos, pero cada p’urhépecha había entregado un tomín (lo que nos llevaría a un total de 160 personas). Sin embargo, Diego Tzurequi decía que los 20 pesos correspondían a dos entregas separadas, lo que resultaría en un grupo de 80 tributarios. Una tercera excepción sí es compartida por todos los testigos y tiene que ver con la entrega número 9 del segundo año: un tomín por cada 3 personas, llegando a un total de 3 pesos y 2 tomines (lo que correspondería a 78 contribuyentes).

${ }^{52}$ Conforme a los testigos, cada dos mujeres hacían una pieza de textil. Sin embargo, Pedro Tzutirani, Andrés Cahmahchacu, Alonso Quema y Juan Vanizcume pensaban que 
Tzirosto y sus sujetos contaban con 1,372 tributarios, los de Corupo conformarían un poco menos de $6 \%$. Este número reducido requería la presencia de un sólo uhcambeti ya que este tipo de oficial generalmente atendía cierta cantidad máxima de tributarios. ${ }^{53}$ En el periodo bajo revisión, probablemente correspondiente a los años 1562-1563, el mandón Cristóbal les quitó a sus empadronados un promedio de unos 3 tomines por tributario en el primer ańo, subiendo la cuota a poco más de 10 tomines en el segundo. ${ }^{54}$ Para fines de comparación hay que recordar que en 1560 el alcalde mayor sugirió una cuota de 6 tomines por tributario, cantidad que a raíz de las visitas de Puga y Valderrama pronto subió a 8 tomines (1 peso) y media fanega de maíz por año.

A juzgar por la información contenida en los testimonios, Cristóbal Tzurequi era un oficial que ya tenía por lo menos dos años en el cargo y que ejercía un amplio control sobre los p'urhépecha de San Francisco Corupo, a quienes cobraba tributos y asignaba trabajos en sementeras de terceros, aumentando las cuotas y sustrayendo el dinero de la caja local (la vasija) para fines no especificados, amenazando a quienes se atrevían a oponerse a sus acciones. Quizá el indicador más claro de su estatus e influencias fue el hecho de que las quejas en su contra, realizadas ante el gobernador don Pedro de Tzirosto, no tuvieron ningún efecto más allá del registro de algunos testimonios. En la localidad, Cristóbal, al parecer, gozaba de los privilegios de un señor y por lo tanto no debe sorprender que el juicio de residencia realizado por Juan de Baeza (1564) se refiera a él como

la producción total había sido de 25 piezas (entonces 50 trabajadoras) mientras que Diego Tzuraqui y Juan Tzurequi se referían a únicamente 20 piezas (que corresponderían a 40 productoras). Por su parte el uhcambeti argumentaba que se entregaron 21 piezas, lo que nos llevaría a una cifra de 42 responsables.

${ }^{53}$ En 1590, en el caso de Pátzcuaro y sus barrios, se calculaban 100 tributarios por cada oficial. Paredes Martínez et al., Y por mí visto.., p. 311. En la época prehispánica, la asignación al parecer se determinaba a partir de un número de 25 casas, lo que implicaba cierta variación en el número de habitantes y por ende también de cautivos de impuestos. Alcalá, Relación de las cerimonias..., p. 558.

${ }^{54}$ Se trata de una cifra aproximada en que para el segundo año también se ha tomado en cuenta el pago de las mujeres como si este hubiera estado a cargo de los 80 tributarios. No contabilizamos las cargas adicionales que fueron negadas por el uhcambeti y cuya inclusión aumentaría el promedio con menos de un tomín. 
cacique. Por la falta de datos, muchas preguntas sobre su identidad, sus relaciones y su conducta permanecerán en el aire. Sería interesante saber si era un noble de linaje antiguo o una persona que había ganado prestigio precisamente a través del ejercicio de su oficio. De la misma manera nos gustaría disponer de información sobre su relación con el gobernador don Pedro Cutao de Tzirosto, a quien el oficial local debía haber entregado una determinada cantidad de los tributos recolectados. La recaudación total de los diferentes uhcambecha servía para el pago de la cuota al encomendero y los gastos de la propia república de indios. Es posible que el mandón de San Francisco simplemente haya cobrado una cuota mayor a la establecida en la tasación oficial impuesta por la cabecera, de esta manera aprovechando la diferencia para su propio sustento y acumulación de riqueza, más allá de la remuneración oficial que debía recibir y cuyo monto desconocemos. ${ }^{55}$ Es decir, se repetiría la misma dinámica que en el caso de los gobernadores que aprovechaban las sobras de los tributos destinados a encomenderos y corregidores. Los abusos por parte de los uhcambecha no eran ninguna novedad y ya habían sido registrados en la década de 1530: "A estos principales llamados ocánbecha, por este oficio no les solían dar más de leña y alguna sementerilla que le hacían y otros le hacían cotaras. Y agora, muchas veces, en achaque del tributo, piden demasiado a la gente que tienen en cargo y se lo llevan ellos, y éstos guardan muchas veces los tributos de la gente $[\ldots] " .{ }^{56}$

Es probable que el control sobre los tributarios y la fuerza de trabajo también haya sido motivo de conflictos locales entre el uhcambeti y otros principales. En este sentido es interesante ver que los testigos Andrés Camahchacu, Alonso Quema y Juan Vanizcume, que estaban entre los acusadores de Cristóbal Tzurequi, no se asumían como parte de los p'urhépecha sino que hablaban de ellos en tercera persona, lo que podría indicar que gozaban de un estatus mayor. Por otro lado, los declarantes Diego Tzuraqui, Juan Tzurequi y

${ }^{55}$ En 1580, los tequitlatos de Aquila y sus barrios recibían un sueldo de 2 fanegas de maíz por oficial. Paredes Martínez et al., Y por mi visto.., p. 175.

${ }^{56}$ Alcalá, Relación de las cerimonias..., p. 559. 


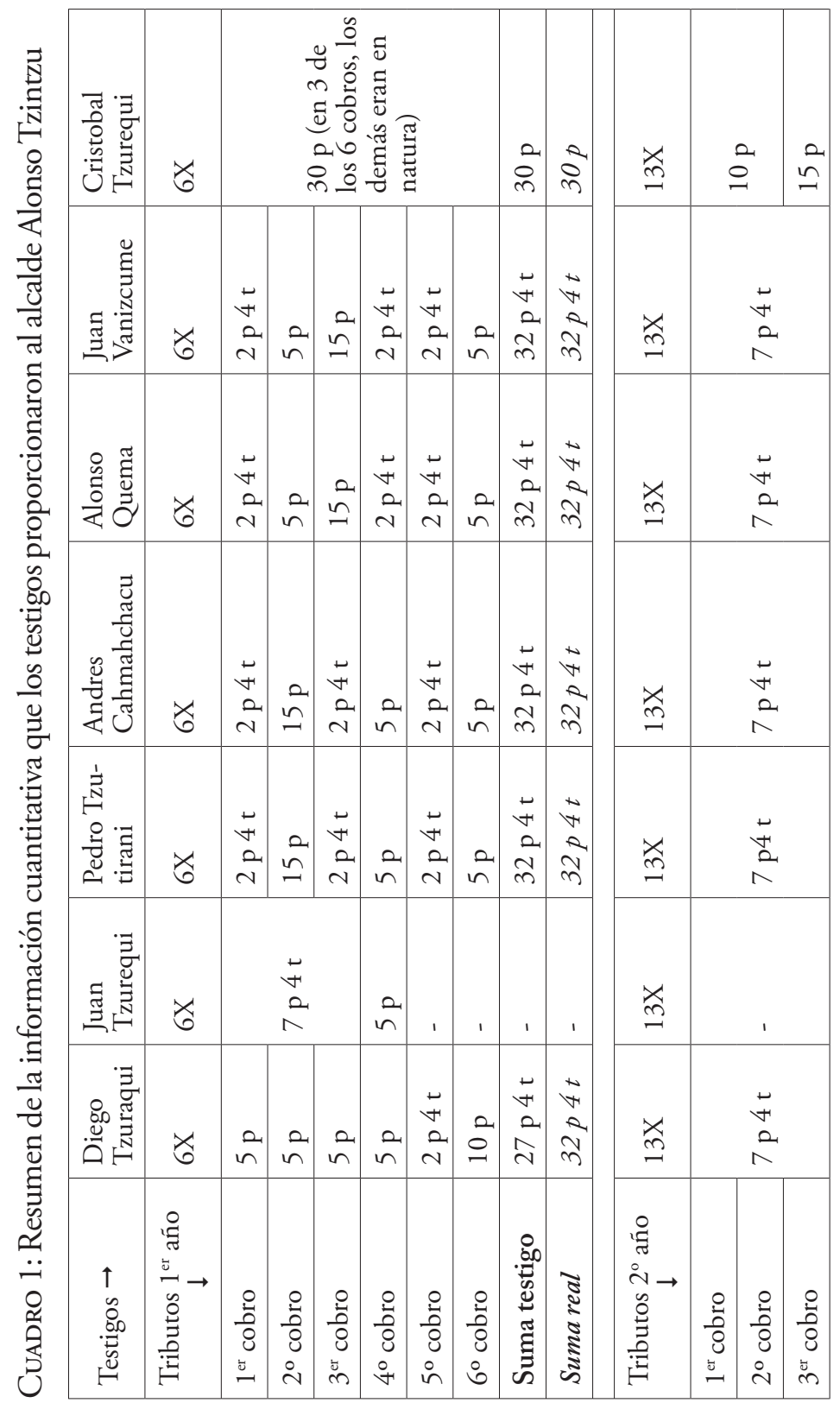




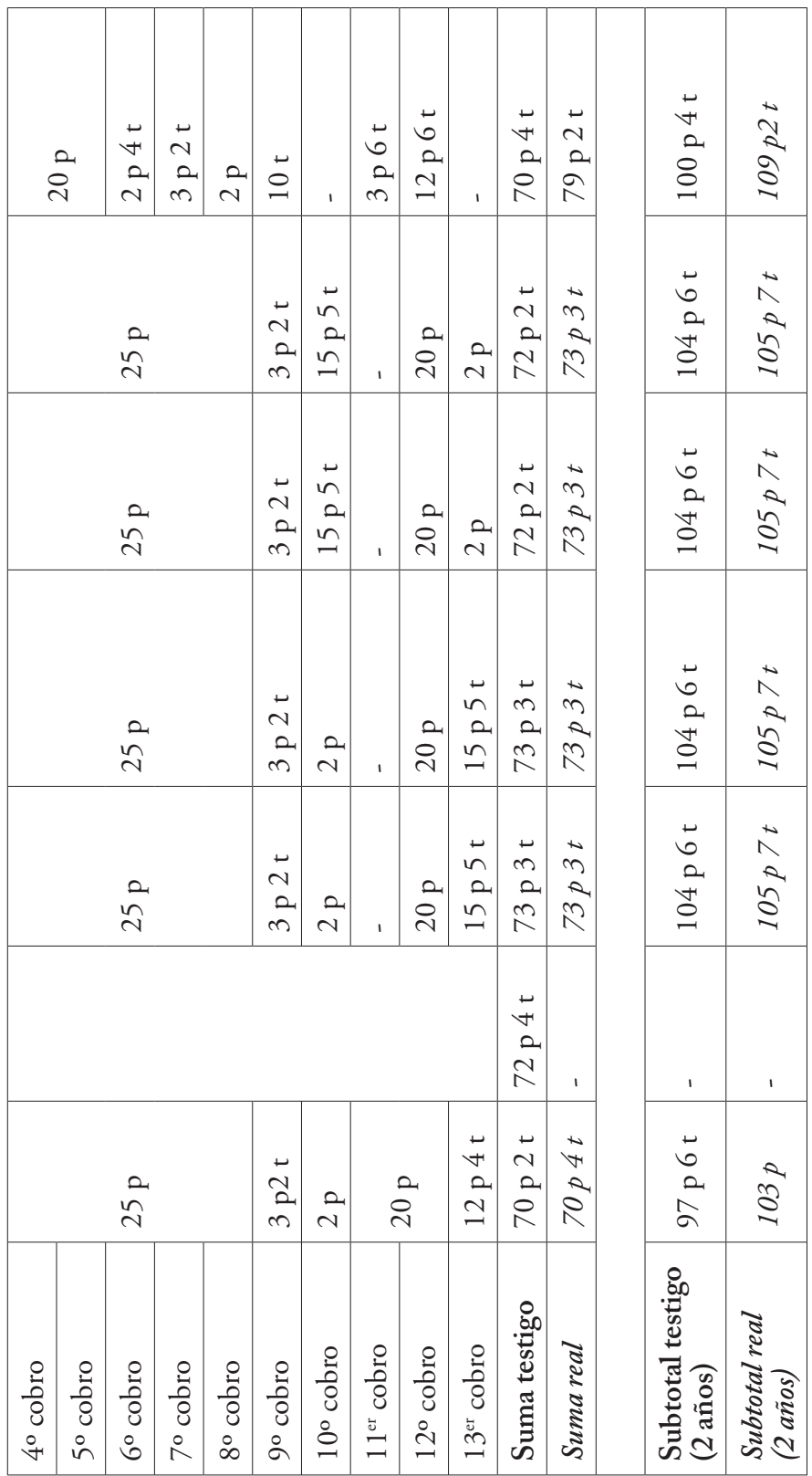




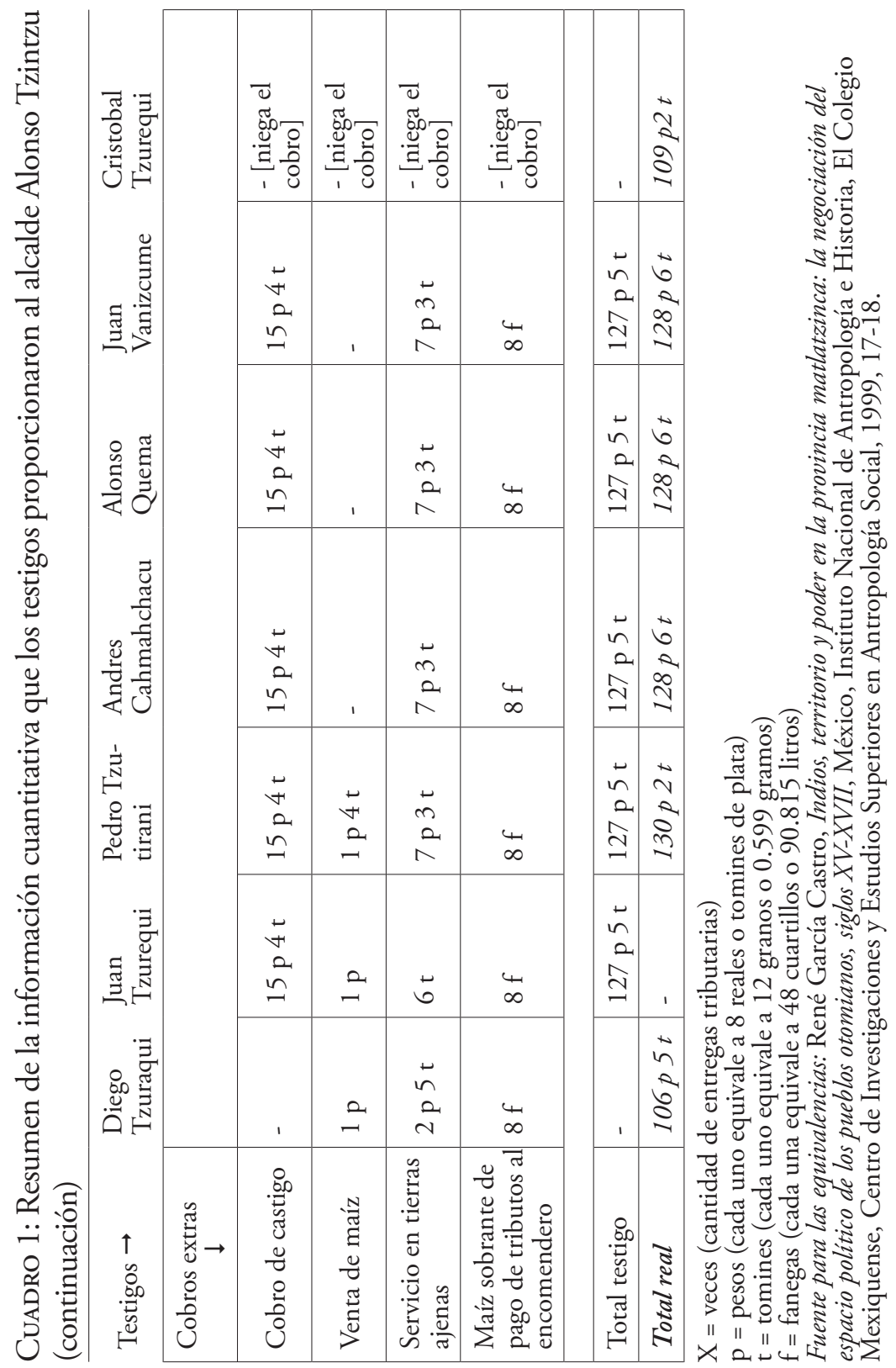


Pedro Tzutirani sí se identificaban como macehuales y los primeros dos incluso habían realizado actividades laborales en tierras de Vanizcume. Teniendo en cuenta que los naturales de San Francisco escogieron sus propios testigos, al parecer existía una alianza entre los p'urhépecha y algunos nobles locales para denunciar los supuestos abusos de su mandón Cristóbal Tzurequi. Estas acciones ocurrieron precisamente en una época en que todos los gobiernos locales y sus finanzas estaban siendo revisados de manera profunda, precisamente con el fin de mejorar y regular la recaudación de tributos, lo que implicaba una limitación de las libertades y poder de los diversos oficiales en la cabecera, pero también de los sujetos. Esta coyuntura era aprovechada no sólo para remediar situaciones de abuso real sino también para liquidar cuentas pendientes entre los oficiales, diversas facciones de nobles y los propios macehuales.

\section{ApÉNDICE}

Traducción de los testimonios registrados en lengua tarasca por el alcalde de Tzirosto en San Francisco Corupo, el 20 de diciembre de 1563 (АНСР, Caja 131, Legajo 3 [SP112], fojas sin numeración).

San Francisco Corupo, a veinte de diciembre. Vine a este pueblo porque su seńoría don Pedro tiene el mandato de gobernador. Yo, don Alonso Tzintzu, alcalde de Tzirosto, os escucho a vosotros habitantes de San Francisco Corupo, empadronados en Santa Ana Tzirosto -Francisco Zintzu, Martín Tena, Juan Evatsi, Bartolomé Tangutsi, Melchor Quaraqui y también Martín Tangutsi-, y a todos los purépecha habitantes de este San Francisco Corupo. Yo os escucho.

En cuanto vosotros pedís justicia; en cuanto el uhcambeti Cristóbal anda ocultándoos los tomines al quitaros aquellos que vosotros pusisteis en una vasija; el problema, pues, por el cual vosotros os andáis quejando tanto. Por cuanto atañe a la verdad, quizás los habitantes de San Francisco Corupo añadan algo respecto del uhcambeti Cristóbal; vosotros pondréis los testigos para que yo imparta buena justicia. Así os lo digo, yo, el alcalde don Alonso Tzintzu, es- 
tando aquí en este San Francisco Corupo. [rúbricas] ${ }^{57}$ Don Alonso Tzintzu. Martín Vuapeme, escribano.

Yo, Diego Tzuraqui, habitante de San Francisco Corupo, empadronado en Tzirosto, ya quiero prestar juramento; yo acostumbro hablar derecho. El año pasado nosotros sacamos [los tomines], ciertamente se pusieron seis veces en una vasija. Nosotros los sacábamos de la siguiente manera: de cada persona medio tomín. Ciertamente se perdieron. ${ }^{58}$ En total [el uhcambeti] guardó cinco pesos en una vasija. Además, tres veces nosotros sacamos medios tomines; en total fueron 15 pesos. Era el uhcambeti Cristóbal el que los tenía guardados, los ponía en una vasija. En tanto somos purépecha, todos nosotros acostumbramos ponerlos en una vasija. Y ¡ a dónde se llevaba tanto?, por eso es el pleito allá en Tzirosto. Y también, por segunda vez, a nosotros, a cada dos personas, nos quitaron una carga. ${ }^{59}$ Ciertamente se perdieron. En total se nos quitaron dos pesos con cuatro tomines. Y ciertamente también, el uhcambeti Cristóbal nos quitó un tomín a todos los purépecha; entonces en total puso en una vasija diez pesos. La sexta vez, nosotros sacamos los tomines, se pusieron en una vasija. El primer año fueron tantos. Los tomines juntos fueron 27 pesos con cuatro tomines. Nosotros tanto así sacamos; los tomines se guardaron en una vasija, por eso el pleito.

Y durante el segundo ańo 13 veces los sacamos para que se pusiesen en una vasija. Primero sacamos tres veces cada uno una carga. Ciertamente se perdieron. En total fue él, [Cristóbal], el que metió 7 pesos con 4 tomines. Yo ciertamente vi cuando eran recibidos. Además, cinco veces nosotros los sacamos, quitándosenos medios tomines. En total, puso en una vasija 25 pesos. Yo ciertamente vi los tomines. Así mismo, nosotros sacamos un tomín por cada tres personas. Ciertamente se perdieron. Entonces, en total, puso tres pesos con dos tomines. Y además, nosotros, por [cada] cinco personas,

${ }^{57}$ Las palabras entre corchetes han sido introducidas por el traductor.

${ }^{58}$ La traducción corresponde al término tarasco 'ahtsinstani' que se ha reconstruido aquí para la palabra del texto tarasco 'tsimintzahco'. Las diferencias entre ambas dan lugar a considerar la traducción como probable.

${ }^{59} \mathrm{El}$ texto tarasco al hacer mención de la carga, no indica cual es el objeto cargado. 
también sacamos un tomín. Ciertamente se perdieron. Entonces puso dos pesos en una vasija. Igualmente, dos veces a nosotros, todos los purépecha, se nos quitó un tomín. Ciertamente se perdieron. En total guardó en una vasija 20 pesos. Y también las viudas y aquellas que nosotros casamos hicieron faldas, cada dos personas hicieron una. En total, se cosieron 20 y allá en Pequaro, en la casa hospital, se vio. El precio era de cuatro, [más bien] cinco. Por cada falda se reciben tomines, [cada una] costaba 5 tomines. Así nosotros sacamos y se pusieron en una vasija 12 pesos con cuatro tomines. Décimo tercero, en el segundo año en total fueron 70 pesos con 2 tomines, tanto así, el uhcambeti Cristóbal, nos quitó. Lo ando diciendo en cuanto el pleito será sacado. Así me acuerdo que en total, por dos, ańos fueron 97 pesos con 6 tomines. Yo ciertamente vi los tomines que el uhcambeti Cristóbal nos quitó.

Y también otra cosa, los purépecha dicen que el uhcambeti Cristóbal les quitó a uno un peso, a otro 2 tomines, a otro más 4 tomines y a otro 6 tomines. Yo muy al principio no vi los tomines que les quitaron; esos tomines no los vi. ¿Por qué mentiría al hablar? No vi los tomines que les quitaron. Los purépecha hablan mucho, escriben. ¿Acaso los escucharon en relación con lo que ellos les quitaron? Escriben. No vi los tomines. ¿Yo por qué mentiría? Y también otra cosa, el señor Alonso Tziquan, para el cual nosotros trabajamos sus haciendas, reunió a todos los purépecha. Por un peso nosotros labramos para él, fue el uhcambeti Cristóbal el que lo recibió, el que lo guardó. Así mismo, el escribano se fue con un peso, para él todos los trabajadores lo sacaron, fue el uhcambeti Cristóbal el que también lo recibió, lo guardó. Dos tomines de [Martín] Tangutsi salieron porque labramos para él, el uhcambeti Cristóbal recibió 2 tomines; 2 tomines de Domingo Tangutsi por labrarle sus tierras, fue el uhcambeti Cristóbal el que los recibió; 2 tomines de Alonso Hinaqua debido a que nosotros le labramos sus tierras, fue el uhcambeti Cristóbal el que los recibió; y uno de Juan Vanazcume. En total 10 pesos fue el valor de los tomines que Cristóbal les quitó. Yo ciertamente vi cuando los quitó. Así juntos en total fueron cuatro pesos; Cristóbal los guardó y no se los mostró a los purépecha, a aquellos que trabajaron hacienda ajena. Yo ciertamente vi cuatro 
pesos. Y el peso que se sacó del maíz de la comunidad se ha devuelto, de aquel maíz que se llevaba a Pátzcuaro. Aquel Cristóbal no lo mostró, lo guardó. Y las 8 fanegas de la tasación de maíz del señor Francisco de Villegas que sobraron, aquel uhcambeti Cristóbal las guardó. Yo ciertamente lo vi. Respecto a todo lo que dije, no he mentido porque soy una persona que ciertamente habla derecho; porque soy un anciano, pero no llevo la cuenta de todos los ańos que tengo. Yo, Diego Tzurequi.

Yo, Juan Tzurequi, habitante de este San Francisco Corupo, empadronado en Santa Ana Tzirosto, yo ciertamente quiero ahora prestar juramento. El año pasado comencé a reunir a la gente, se pusieron tomines en una vasija. Seis veces nosotros los sacamos. Primero, tres veces sacamos cada uno una carga. Ciertamente se perdieron. En total se recibieron 7 pesos con cuatro tomines. Y también a nosotros se nos quitaron unos pequeños medios [tomines], en total fueron 5 pesos. Se recibieron tantos tomines, Cristóbal los guardó. Quinto, sacamos un tomín con medios tomines. Nosotros no los vimos. ¿Dónde se recibieron tantos tomines? Sexto, fue a nosotros, a todos los purépecha, a quienes se nos quitaron medios tomines. No vimos donde estaban tantos tomines cuando se contaron los que se tenían. Así transcurrió un año.

El segundo año nosotros comenzamos poniéndolos en una vasija 13 veces. Primero, nosotros seis veces los sacamos, poniéndose medios tomines en una vasija. ¿Dónde se guardaron tantos tomines? No lo vimos. Y dos veces nosotros sacamos cada uno una carga; se pusieron en una vasija. ¿¿Dónde [se pusieron] No vimos. ${ }^{60} \mathrm{Y}$ dos veces nosotros, a cada uno, también les sacamos un tomín. Ciertamente se perdieron. Y además, nosotros, por cada tres personas, sacamos un tomín. Y también nosotros, de uno en uno, sacamos un tomín. ¿¿ónde [se pusieron] tantos tomines? No

${ }^{60}$ Con doble subrayado indicamos la presencia de una mancha en el documento. Reconstruimos siguiendo lo expresado en la sexta oración de la segunda deposición debido a que ésta inicia igualmente con nanti, además en la zona manchada se logra ver una ' $n$ ' inicial, una diagonal que podría ser parte de una ' $x$ ' y finalmente porque la palabra termina en ca. 
vimos. Así mismo aquellas que nosotros casamos y también las viejas hicieron faldas; dos personas hicieron una. En total fueron 20. Así juntos, en un año, pusieron en una vasija 72 pesos con cuatro tomines. He hablado derecho, no he estado mintiendo, tanto así fue lo que el uhcambeti Cristóbal les quitó en estos dos años.

Y otra cosa también, "Uhcambeti Cristóbal, algo les quitaste a aquellos que llamaste, a los que andabas regañando, a los que les criticabas lo que hacían. A aquellos que se quejaban tú les quitaste a unos un peso, a otros 6 tomines, a unos 4 tomines, a otros 10 tomines". Todos ellos eran 10. Y para ellos se hizo la cuenta de 15 pesos con cuatro tomines. Yo muy bien sé que así se los quitó este uhcambeti Cristóbal. Y también sé que del maíz de la comunidad que se llevaba a Pátzcuaro, un peso se ha devuelto. Cristóbal lo guardó, no se los mostró. Además nosotros, todos los purépecha, fuimos a labrar para el señor Alonso Tzuquan [¿Tziquan?]. Un peso es lo que recibimos en pago. Fue el uhcambeti Cristóbal el que lo guardó, no se los mostró. Así mismo, para la rencilla del escribano también se nos quitó un peso, tampoco lo mostró. Y dos tomines de Alonso Hinaqua, porque nosotros también labramos para él, el uhcambeti Cristóbal también los guardó; dos tomines de Martín Tangutsi, porque nosotros labramos para él. "Y para ti, Juan Vuazcume, labramos por dos tomines”. Y aquel uhcambeti Cristóbal los guardó. Igualmente, las 8 fanegas de maíz del señor Francisco de Villegas que sobraron, las guardó aquel uhcambeti Cristóbal. Yo ciertamente lo vi, no acostumbro andar hablando con mentiras; yo hablo derecho en la medida en que tanto [...] hablo. Yo, Juan Tzurequi. En total fueron 127 pesos con 5 tomines.

Yo, Pedro Tzutirani, habitante de San Francisco Corupo, empadronado en Tzirosto, yo quiero hacer ahora juramento; yo acostumbro hablar derecho. Todos los purépecha, que muchas veces en verdad se quejan, pusieron los tomines en una vasija. Primeramente el ańo pasado todos los purépecha seis veces los sacaron para ponerlos en una vasija. Primero, todos los purépecha sacaron cada uno una carga; en total se sacaron dos pesos con cuatro tomines. Segundo, todos los purépecha sacaron cada persona un tomín y medio; en total 
fueron 15 pesos. Tercero, todos los purépecha sacaron cada uno una carga; en total se recibieron 2 pesos con cuatro tomines. Cuarto, todos los purépecha sacaron también medios tomines; en total pusieron en una vasija 5 pesos. Quinto, sacaron cada uno una carga, todos los purépecha las pusieron en una vasija; en total se recibieron dos pesos con cuatro tomines. Sexto, fueron medios tomines los que sacaron, todos los purépecha los pusieron en una vasija; en total fueron 5 pesos. Se dice que así juntos, en un ańo, en total se sacaron y guardaron 32 pesos con cuatro tomines. Tantos tomines guardó el uhcambeti Cristóbal.

Durante el segundo año, además, trece veces los sacaron para ponerlos en una vasija. Primero, sacaron cada uno una carga para ponerlas en una vasija. Cristóbal tres veces se las quitó a todos los purépecha; en total se recibieron 7 pesos con cuatro tomines. También el uhcambeti Cristóbal cinco veces les quitó a todos los purépecha medios tomines, entonces en total fueron 25 pesos. Noveno, les quitó a todos los purépecha, a cada tres personas un tomín, entonces en total fueron tres pesos con 2 tomines. Todo eso les quitó el uhcambeti Cristóbal. Décimo, les quitó a todos los purépecha, a cada cinco personas un tomín, entonces en total pusieron en una vasija 2 pesos. Décimo segundo, fue el uhcambeti Cristóbal el que les quitó a todos los purépecha 2 tomines, entonces en total fueron 20 pesos. Tantos se contaron. Yo mismo lo vi. Décimo tercero, las viudas con todas las mujeres hicieron faldas; el uhcambeti Cristóbal las hizo hacerlas, de dos en dos hicieron cada una. En total se pusieron en una vasija 25 vestidos. Cada vestido valía cinco tomines; en total se recibieron 15 pesos con 5 tomines. Así juntos en un ańo el total fue de 73 pesos con 3 tomines. Todo eso les quitó el uhcambeti Cristóbal. Se dice que por dos años fue un total de 104 pesos con 6 tomines. Todo eso les quitó el uhcambeti Cristóbal.

Y también otra cosa, ¿qué destino anduvo diciéndoles a esos que les quitó los tomines? Les quitó los tomines a todos aquellos que verdaderamente se quejaban. En total, fueron 15 pesos con 4 tomines. A los purépecha fue a los que el uhcambeti Cristóbal se los quitó. En verdad les quitó los tomines, no es mentira. Igualmente no les mostraba los tomines del maíz de la comunidad que se llevaba 
a Pátzcuaro; entre tanto los tomines se han devuelto. Y también de ahí de donde todos los purépecha labrábamos hacienda ajena salió un peso con cuatro tomines, tampoco se los mostró. A todos los purépecha les es dulce labrar hacienda ajena y todo esto sumó 7 pesos con 3 tomines. Tanto así se guardó el uhcambeti Cristóbal y no lo manifestó. Y además, las 8 fanegas de maíz del señor Francisco de Villegas que sobraron fueron las que guardó también el uhcambeti Cristóbal. He hablado derecho. Juntos, en total fueron 127 pesos con 5 tomines. Ciertamente tanto he visto. Yo, Juan Tzutiran.

Yo, Andrés Cahmahchacu, habitante de este San Francisco Corupo, empadronado en Tzirosto, quiero ahora prestar juramento; yo acostumbro hablar derecho. En verdad muchas veces se pusieron tomines en una vasija, por eso es el pleito. Fue el uhcambeti Cristóbal el que entonces acumuló [los tomines] puesto que era él el uhcambeti. Entonces comenzó a quitárselos muchas veces. El año pasado se los quitó seis veces. Primero, les quitó a todos los purépecha, a cada uno una carga; en total se recibieron 2 pesos con 4 tomines. Segundo, les quitó a todos los purépecha, a cada uno un tomín y medio; en total fueron 15 pesos. Tercero, les quitó a todos los purépecha, a cada uno una carga, entonces en total fueron 2 pesos con 4 tomines. Cuarto, les quitó a todos los purépecha medios tomines, entonces fueron 5 pesos. Quinto, les quitó a todos los purépecha, a cada uno una carga, entonces en total se recibieron 2 pesos con 4 tomines. Sexto, aquel uhcambeti Cristóbal les quitó medios tomines, entonces el total fue de 5 pesos. Así juntos en un año, el total fue de 32 pesos con 4 tomines. Tanto así el uhcambeti Cristóbal les quitó.

Durante el segundo año también se sacaron tomines, y trece veces se pusieron en una vasija. Primero, por tres veces les quitó a todos los purépecha una carga a cada uno; en total se recibieron 7 pesos con 4 tomines. Además, cinco veces les quitó a todos los purépecha medios tomines, en total fueron 25 pesos. Noveno, les quitó a cada tres personas un tomín, fue a todos los purépecha a los que se los quitó el uhcambeti Cristóbal, en total fueron 3 pesos con 2 tomines. Décimo, les quitó a todos los purépecha, a cada cinco personas un tomín; [en total fueron] 2 pesos. Décimo segundo, Cristóbal les quitó a todos los pu- 
répecha, a cada cuatro un tomín, entonces en total fueron 20 pesos. Décimo tercero, todas las mujeres y las viudas hicieron faldas; dos personas hicieron una. En total fueron 25 vestidos, cada vestido valía cinco tomines; en total se recibieron 15 pesos con 5 tomines. Así juntos en un año el total fue de 73 pesos con 3 tomines, tanto así les quitó el uhcambeti Cristóbal. Así en dos ańos el total fue de 104 pesos con 6 tomines. Tal monto les quitó, por eso es el pleito.

Y otra cosa también, el uhcambeti Cristóbal les anduvo diciendo a aquellos a quienes les quitó los tomines que los purépecha a ningún lugar irían, y que por ello considerasen un poco su destino respecto al irse. Y verdaderamente les quitó [tomines] a todos aquellos que se quejaban. En total fueron 15 pesos con 4 tomines. En verdad Cristóbal se los quitó, no es mentira. Ciertamente a causa de ello todos los purépecha se quejan, aquellos a quienes les quitaron los tomines. Es la verdad. [En total fueron] 15 pesos con 4 tomines. Y así mismo, fue el maíz de la comunidad el que se llevaba a Pátzcuaro y los tomines se guardaban poniéndolos en una vasija; no se los mostraba a todos los purépecha. Además, a todos los purépecha que labraban hacienda ajena no les mostraba los tomines, aquellos que todos los purépecha pagaban. Los acumulaba. En total fueron 7 pesos con 3 tomines, el uhcambeti Cristóbal tanto así guardó. ¿En qué lugar estarán? Es verdad, no es mentira. Y también, el maíz por el que todos los purépecha se quejan, las 8 fanegas sobrantes de Francisco de Villegas, fueron las que guardó el uhcambeti Cristóbal. Es la verdad, ciertamente yo lo vi, no es mentira. Todas estas cosas se dicen. En total fueron 127 pesos con 5 tomines. Ciertamente yo lo vi. Yo, Andrés Cahmahchacu.

Yo, Alonso Quema, habitante de San Francisco Corupo, empadronado en Santa Ana Tzirosto, ahora quiero prestar juramento; yo les hablo derecho. Fue el uhcambeti Cristóbal el que en verdad muchísimas veces les quitó los tomines. Hay pleito debido a que se llevó lo que se había puesto en una vasija. Y en verdad el año pasado seis veces les quitó los tomines. Primero, el uhcambeti Cristóbal les quitó a cada uno una carga; fue a todos los purépecha a quienes se las quitó, tanto así fue. Se recibió en total 2 pesos con 4 tomines. Segundo, les 
quitó a todos los purépecha, a cada persona medio tomín, entonces en total fueron 5 pesos. Tercero, les quitó a todos los purépecha, a cada persona un tomín y medio, entonces en total fueron 15 pesos. Cuarto, les quitó a todos, a todos los purépecha, a cada uno una carga; en total se recibieron 2 pesos con 4 tomines. Quinto, les quitó a cada uno una carga; en total se recibieron dos pesos con 4 tomines. Sexto, les quitó a todos los purépecha medios tomines, entonces en total fueron 5 pesos. Así juntos en un ańo fueron en total 32 pesos con 4 tomines. Tanto así les quitó el uhcambeti Cristóbal.

Y el segundo año en total les quitó trece veces aquello que les había hecho poner en una vasija. Primero, todos los purépecha sacaron [los tomines] para ponerlos en una vasija. Tres veces les quitó a todos los purépecha, a cada uno una carga; en total se recibieron 7 pesos con 4 tomines. Y cinco veces les quitó a todos los purépecha medios tomines; en total fueron 25 pesos. Noveno, les quitó a todos los purépecha, a [cada] tres personas un tomín; en total fueron 3 pesos con 2 tomines. Décimo, hizo que hicieran faldas, todas las mujeres y las viudas las hicieron; dos personas hicieron una. En total cosieron 25; entre dos dan un vestido [el cual] valía 5 tomines. En total se recibió 15 pesos con 5 tomines, tanto así guardó el uhcambeti Cristóbal. Décimo segundo, les quitó a todos los purépecha, a cada uno un tomín; en total fueron 20 pesos. Y décimo tercero, les quitó a todos, por cada cinco personas un tomín; en total fueron 2 pesos. En un año, así juntos, en total fueron 72 pesos con 2 tomines. Hasta ahora el uhcambeti Cristóbal, habitante de San Francisco Corupo, tanto les ha quitado. Así se dice que en dos años se contaron un total de 104 pesos con 6 tomines. Tanto he visto yo, no ando diciendo mentiras, tanto el uhcambeti Cristóbal les quitó.

Y otra cosa, a aquellos que se quejan, a aquellos a quienes les quitó los tomines, el uhcambeti Cristóbal les anduvo diciendo que a ningún lugar irían, así les anduvo diciendo. Les quitó a unos un peso, a otros 10 tomines, a otros 6 tomines. En verdad se los quitó. No, no es mentira. En total se contaron 15 pesos con 4 tomines. Es verdad. ¿En tanto Cristóbal se los quitó cuántos purépecha lo hicieron? Yo bien lo sé. No es mentira. ¿Acaso cada uno de los purépecha en verdad [no] se ha quejado? Y también otra cosa, en este pueblo no 
les mostraba los tomines del maíz de la comunidad que se llevaba a Pátzcuaro, aquellos que se han devuelto. Es la verdad. Además, todos los purépecha que labraban hacienda ajena recibían unos un peso, otros 6 tomines, otros 2 tomines. Hubo ganancias; no se las mostró; él mismo ciertamente se las apropió aumentando [su caudal]. En total se contaron 7 pesos con 3 tomines, tanto así el uhcambeti Cristóbal guardó. ¿¿Dónde andarán? A nosotros, a todos los purépecha, no nos hicieron saber a dónde se los llevó. Además, también sobraron 8 fanegas del maíz que pertenecía a Francisco de Villegas y del cual se quejaron durante dos años. Así juntos, el total fue de 127 pesos con 5 tomines, tanto ciertamente yo vi. Yo, Alonso Quema.

Yo, Juan Vanizcume, habitante de San Francisco Corupo, empadronado en Santa Ana Tzirosto, ahora quiero prestar juramento. Ciertamente yo bien vi todo en tanto tantas veces el uhcambeti Cristóbal puso [tomines] en una vasija. En breve, unos 1 tomín, otros un medio, otros una carga, así acostumbraba hacerlo. Y por eso ciertamente todos los purépecha se quejaron durante dos ańos. Primeramente el año pasado nosotros seis veces sacamos [tomines] para ponerlos en una vasija. Primero, les quitó a todos los purépecha, a cada uno una carga, entonces en total puso en una vasija 2 pesos con 4 tomines. Segundo, Cristóbal les quitó a todos los purépecha medios tomines; en total fueron 5 pesos. Tercero, les quitó a todos los purépecha, a cada persona un tomín y medio; en total fueron 15 pesos. Cuarto, les quitó una carga a cada uno; en total se recibieron 2 pesos con 4 tomines. Quinto, también les quitó a todos los purépecha una carga a cada uno; en total fueron 2 pesos con 4 tomines. Sexto, les quitó medios tomines, entonces en total fueron 5 pesos. En un año, así junto, hicieron un total de 32 pesos con 4 tomines. Tanto así el uhcambeti Cristóbal les quitó.

Durante el segundo año Cristóbal trece veces les quitó tomines. Primero, tres veces les quitó a todos los purépecha una carga a cada uno; en total recibió 7 pesos con 4 tomines. Además, cinco veces les quitó a todos los purépecha medios tomines, entonces en total fueron 25 pesos. Noveno, les quitó a todos los purépecha, a cada tres personas un tomín; en total fueron 3 pesos con 2 tomines. Décimo, 
las hizo hacer faldas; todas las mujeres y las viudas las hicieron, dos personas hicieron una. En total cosieron 25 vestidos. 5 tomines es lo que valía un vestido; en total se recibieron 15 pesos con 5 tomines. Tanto se guardó el uhcambeti Cristóbal. Décimo segundo, les quitó a todos los purépecha, a cada uno tomines. Los anduvo induciendo al temor, y también los anduvo privando de su libertad. En total puso en una vasija 20 pesos. Décimo tercero, les quitó a todos, a cada cinco personas un tomín, entonces en total fueron 2 pesos. En un año, así juntos, en total fueron 72 pesos con 2 tomines. Hasta ahora en total el uhcambeti Cristóbal, habitante del pueblo de San Francisco Corupo, se los quitó. Así en dos ańos el total fue de 104 pesos con 6 tomines. Tanto así yo vi, no he mentido al hablar, ese fue el total.

Y también otra cosa, a aquellos que se quejan, a aquellos que les quitaron los tomines, ‘̇acaso a unos se les quitó un peso, a otros 10 tomines, a otros 6 tomines, a otros más 4 tomines, a otros 2 tomines? Así andaban expresando su sentir, en tanto que ellos no irían a ningún lugar por lo que considerasen un poco los hechos respecto a él. Y por otra parte así andaban expresando su sentir. Obligó a los purépecha, los envió a algún lugar, por eso ellos se quejan. En total se contaron 15 pesos con 4 tomines. El uhcambeti Cristóbal les quitó todo eso, es la verdad. Yo bien lo sé, y ciertamente también lo vi, no es mentira, en verdad el uhcambeti Cristóbal se los quitó. Y otra cosa también, aquellos que se quejan, aquellos que en este pueblo llevaban a Pátzcuaro el maíz de la comunidad, y aquellos que eran inducidos a dar dinero no lo manifestaban. ¿No fue el uhcambeti Cristóbal el que lo guardaba? No se los mostraba a los purépecha. ¿No lo guardó él sin ayuda de nadie? Además, todos los purépecha, los que también habían sido obligados para beneficio de algunos, ¿acaso hicieron ganancias unos con el valor de un peso, otros con dos tomines? Así juntos, en total se contaron 7 pesos con 3 tomines; él también a sí mismo se los atribuía. Fue el uhcambeti Cristóbal el que guardaba los tomines, ciertamente yo lo vi; no es mentira. Y otra cosa también, en total sobraron 8 fanegas de maíz del Sr. Francisco de Villegas, que se dice que fue llevado y entregado en dos años. Las guardó el uhcambeti Cristóbal. ¿Por dónde andarán? Los purépecha no lo vieron. Empero yo ciertamente muy bien 
vi las 8 fanegas sobrantes; no acostumbro mentir al hablar, es la verdad. Respecto a todo lo que he dicho, no he mentido, he hablado derecho porque soy cristiano. ¿No moriré acaso?, ¿por qué les mentiría al hablar? Y no aprendí a escribir. Yo, Juan Vanazcume. En total fueron 127 pesos con 5 tomines.

Yo, don Alonso Tzintzu, alcalde de Tzirosto, os escucho, aquello que dijisteis, tú, Diego Tzurequi, Juan Tzurequi, y tú, Pedro Tzutiran, y tú, Andrés Camahchacu y Alonso Quema, y también tú, Juan Vanazcame. Así os escucho con buena crianza a vosotros habitantes de San Francisco Corupo, empadronados en Santa Ana Tzirosto. Estando en este San Francisco Corupo se escribe hoy día 22 del mes de diciembre. [rúbricas] Yo, don Alonso Tzintzu, alcalde, Martín Vuapeme, escribano.

Así juntos se cuentan 127 pesos con 5 tomines. Es el uhcambeti Cristóbal Tzurequi el que se los quitó. Yo, don Alonso, alcalde de Tzirosto, estando ahora en San Francisco Corupo.

Segundo, ellos no preguntan, y vosotros ¿Acaso habláis derecho? Vosotros tenéis buena crianza: tú, Diego Tzurequi, y tú, Juan Tzurequi, y tú, Pedro Tzutiran, y tú, Andrés Camahchacu, y tú, Alonso Quema, y tú, Juan Vanazcume, habitantes de San Francisco Corupo, empadronados en Tzirosto. Vosotros siempre decís que hablasteis derecho, que no mentisteis respecto a todo lo que dijisteis, así acostumbráis decir. Yo, don Alonso Tzintzu, alcalde, os escucho, estando en San Francisco Corupo el día 22 del mes de diciembre. [rúbricas] Yo, don Alonso Tzintzu, alcalde. Martín Vuapeme, escribano.

Yo, el uhcambeti Cristóbal Tzurequi, habitante de San Francisco Corupo, empadronado en Santa Ana Tzirosto, quiero ciertamente prestar juramento. Verdaderamente les quité tomines el año pasado. Seis veces, yo os juro, no se los quité; en verdad a cada uno sólo tres veces les quité tomines. En total fueron 30 pesos, fue el total de tomines que les quité. Es la verdad, me los llevé. Con el pleito me acerco [para que] todo concluya.

Y durante el segundo año os doy a entender que les quité trece veces; es verdad que les quité tanto; en verdad les quité trece veces. 
Primero, dos veces les quité a todos los purépecha, a cada persona unos medios; en total fueron 10 pesos. Tercero, también les quité a todos unos medios, entonces en total él puso en una vasija 15 pesos. Y además, también dos veces les quité a todos los purépecha, a cada uno un tomín, entonces en total fueron 20 pesos. Sexto, les quité a cada uno una carga, entonces en total se recibió 2 pesos con 4 tomines. Séptimo, les quité a todos los purépecha un tomín por cada tres personas, entonces en total fueron 3 pesos con 2 tomines. Octavo, de cinco en cinco les quité un tomín; en total fueron 2 pesos. Noveno, de dos en dos hicieron una carga, yo allá también se las quité, entonces en total fueron 10 tomines. Décimo primero, por pares a todos les quité tres cargas, entonces fue un total de 3 pesos con 6 tomines. Las mujeres hicieron mantas para faldas, en total se pusieron en una vasija 21, y se recibieron 12 pesos con 6 tomines. Así se dice que sucedió. Décimo segundo, por lo tanto yo les quité todos esos tomines. Por un año, así juntos, fueron en total 70 pesos con cuatro tomines. Por dos ańos, así juntos, fueron en total 100 pesos con 4 tomines.

Y también otra cosa, aquello que se dice, que yo tomé y les quité tomines; nada les quité. ¿Acaso esto se dice? Ellos están mintiendo respecto a la tributación de 15 pesos con 4 tomines. Y no es verdad que a alguna persona le quitara un tomín. Y también otra cosa, fue aquel maíz de la comunidad el que se llevaba a Pátzcuaro, y el año pasado en verdad regresó un peso. [Así] pasó. Y ya el año pasado en total se sacó a San Felipe un peso con cuatro tomines; yo lo supe. Y dos tomines fueron los que se tomaron en pago allá en San Felipe; dos tomines fueron los que yo di a cambio de sal; Pedro Tsiritsi se los llevó. Y fue un peso el que se llevó a Tzirosto, Gonzalo lo llevó. Así, yo ciertamente no me llevé los tomines. Los que hablan respecto a que ellos labraban sementera ajena por muchos tomines, tributaron con maíz por 7 pesos con 3 tomines. Yo no vi nada, empero fue un peso con 2 tomines los que yo mismo vi. Y fue el señor Domingo [Tangutsi] el que se llevó los 10 tomines que ellos me enseńaron. Y aquellos que hablan del maíz sobrante en los dos años, respecto a las 8 fanegas que sobraron, yo no las vi, empero yo llevé el pleito por 90 pesos, lo llevé a la ciudad, ¿Acaso cambié algo con el negocio? 
Yo, Alonso Tzintzu, alcalde de Tzirosto, he escuchado aquello que tú dijiste, tú, uhcambeti Cristóbal Tzurequi, habitante de San Francisco, empadronado en Santa Ana Tzirosto. Estando en San Francisco Corupo se escribe el 22 de este mes de diciembre. [rúbricas] Yo, don Alonso Zintzu, alcalde. Martín Vuapeme, escribano.

\section{BiBLIOGRAFÍA}

Archivos:

Archivo General de Indias (AGI), Patronato, 278, N.2, R.216, Año 1540.

Archivo Histórico de la Ciudad de Pátzcuaro (AHCP), Caja 131, Legajo 3 (SP112), Año 1564.

\section{Libros y revistas:}

Alcalá, Jerónimo de, Relación de las cerimonias y rictos y población y gobernación de los indios de la provincia de Mechuacán, Moisés Franco Mendoza, coordinador de edición y estudios, Zamora, El Colegio de Michoacán, Gobierno del Estado de Michoacán, 2000.

Castro Gutiérrez, Felipe, Los tarascos y el imperio español. 16001740, México, Universidad Nacional Autónoma de México, Universidad Michoacana de San Nicolás de Hidalgo, 2005.

Diccionario Grande de la Lengua de Michoacan, por autor o autores desconocidos, introduccion, paleografia y notas por J. Benedict Warren, 2 tomos, Colección "Fuentes de la Lengua Tarasca o Purépecha” v, Morelia, Fimax, 1991.

El libro de las tasaciones de pueblos de la Nueva España, siglo XVI, Prólogo de Francisco González de Cossío, México, Archivo General de la Nación, 1952.

GARCía CASTRO, René, Indios, territorio y poder en la provincia matlatzinca: la negociación del espacio político de los pueblos otomianos, siglos XV-XVII, México, Instituto Nacional de Antropología e Historia, El Colegio Mexiquense, Centro de Investigaciones y Estudios Superiores en Antropología Social, 1999.

García Martínez, Bernardo, "Trabajo y tributo en los siglos XVI y Xviı", en Gran historia de México ilustrada, México, Editorial 
Planeta, Consejo Nacional para la Cultura y las Artes, Instituto Nacional de Antropología e Historia, vol. II, 2001, 61-80.

García Pimentel, Luis, Relación de los obispados de Tlaxcala, Michoacán, Oaxaca y otros lugares en el siglo XVI. Manuscrito de la colección del señor Don Joaquin García Icazbalceta, en casa del editor, México, 1904.

Karttunen, Frances, An Analytical Dictionary of Nahuatl, Norman y Londres, University of Oklahoma, 1992.

Lagunas, Juan Baptista de, Arte y dictionario con otras obras en lengua michuacana, introducción histórica con apéndice documental y preparación fotográfica del texto por J. Benedict Warren, Morelia, Fimax Publicistas Editores, 2002.

León Alanís, Ricardo, "Los estudios lingüísticos y etnográficos de los religiosos en Michoacán, siglos XVI y XvII", en Carlos Paredes, coord., Lengua y etnohistoria purépecha, Morelia, Universidad Michoacana de San Nicolás de Hidalgo, 1997, 163-178.

Los orígenes del clero y la Iglesia en Michoacán, 1525-1640, México, Universidad Michoacana de San Nicolás de Hidalgo, Instituto de Investigaciones Históricas, 1997.

Márquez JoAquín, Pedro, ¿Tarascos o P'urhépecha? Voces sobre antiguas y nuevas discusiones en torno al gentilicio michoacano, Morelia, Universidad Michoacana de San Nicolás de Hidalgo, El Colegio de Michoacán, Morevallado, 2007.

Martínez Baracs, Rodrigo y Lydia Espinosa Morales, La vida michoacana en el siglo XVI: catálogo de los documentos del siglo XVI del Archivo Histórico de la Ciudad de Pátzcuaro, Colección Fuentes, Instituto Nacional de Antropología e Historia, 1999.

Martínez Baracs, Rodrigo, Caminos cruzados: Fray Maturino Gilberti en Perivan, Zamora, El Colegio de Michoacán, Instituto Nacional de Antropología e Historia, 2005.

Menegus Bornemann, Margarita, Del señorio indigena a la república de indios: El caso de Toluca, 1500-1600, México, Consejo Nacional para la Cultura y las Artes, 1994.

Miranda, José, El tributo indígena en la Nueva España durante el siglo XVI, México, El Colegio de México, 1952.

Monzón, Cristina, "La semilla misionera; una historia de la grafía 
en documentos de amanuenses tarascos durante el siglo Xvi”, en Martina Schrader-Kniffki y Laura Morgenthaler García, eds., Romania en interacción: Entre historia, contacto y politica. Ensayos en homenaje a Klaus Zimmermann, Lengua y Sociedad en el Mundo Hispánico, 18, Frankfurt y Madrid, Vervuert y Iberoamericana, 2007, 179-903.

Monzón, Cristina y Hans Roskamp, "El testamento de doña Ana Ramírez de Acuitzio, Michoacán, 1637”, en Relaciones. Estudios de Historia y Sociedad, núm. 86, 2001, 187-207.

Monzón, Cristina, Hans Roskamp y J. Benedict Warren, "La memoria de don Melchor Caltzin (1543): historia y legitimación en Tzintzuntzan, Michoacán”, en Estudios de Historia Novohispana, Universidad Nacional Autónomo de México, vol. 40, 2009, 21 55.

Paredes Martínez, Carlos, "El tributo indígena en la región del lago de Pátzcuaro", en Carlos Paredes Martínez et al., Michoacán en el siglo XVI, Colección Estudios Michoacanos, vII, Morelia, Fimax Publicistas, 1984, 21-104.

Paredes Martínez, Carlos, "Gobierno y pueblos de indios en Michoacán en el siglo Xvi”, en Carlos Paredes Martínez, director general, Arquitectura y espacio social en poblaciones purépechas de la época colonial, Morelia, Universidad Michoacana de San Nicolás de Hidalgo, Universidad Keio, Centro de Investigaciones y Estudios Superiores en Antropología Social, 1998, 21-45.

Paredes Martínez, Carlos, ed., et al., Y por mi visto... Mandamientos, ordenanzas, licencias y otras disposiciones virreinales sobre $M i$ choacán en el siglo XVI, México, Centro de Investigaciones y Estudios Superiores en Antropología Social, Universidad Michoacana de San Nicolás de Hidalgo, 1994.

Paso y Troncoso, Francisco del, Papeles de Nueva España, Segunda Serie, Madrid, Sucesores de Rivadeneyra, 1905.

Epistolario de Nueva España 1505-1818, México, Antigua Librería Robredo, 1940.

RosKamp, Hans, Los códices de Cutzio y Huetamo: encomienda y tributo en la Tierra Caliente de Michoacán, siglo XVI, Zamora, El Colegio de Michoacán, El Colegio Mexiquense, 2003. 
Seler, Eduard, "Los antiguos habitantes de Michoacán”, traducción de Erika Krieger, confrontación con el original alemán, introducción, corrección y notas de Francisco Miranda, en Jerónimo de Alcalá, Relación de las cerimonias y rictos y población y gobernación de los indios de la provincia de Mechuacán, Zamora, El Colegio de Michoacán, Gobierno del Estado de Michoacán, 2000, 139-233.

Siméon, Rémi, Diccionario de la lengua nábuatl o mexicana redactado según los documentos impresos y manuscritos más auténticos y precedido de una introdución, México, Siglo XXI, 1994.

Talavera Ibarra, Oziel Ulises, Historia del pueblo de indios de San Francisco Uruapan, Morelia, Morevallado Editores, 2008.

Villavicencio, Frida, "Concierto y carta de venta de tierras y casas. Don Antonio Huithsimengari”, en Tlalocan, vol. xIV, 2004, 27-58.

Warren, J. Benedict, “Los estudios lingüísticos en Michoacán en el siglo Xvi: una expresión del humanismo cristiano", en Carlos Herrejón Peredo, ed., Humanismo y ciencia en la formación de México, Zamora, El Colegio de Michoacán, Conacyt, 1984, 113-130.

"Writing the language of Michoacan: sixteenth century Franciscan Linguistics”, en Francisco Morales, ed., Franciscan presence in the Americas, Potomac, Academy of American Franciscan History, 1985, 308-344.

, La conquista de Michoacán, 1521-1530, Colección Estudios Michoacanos, vI, Morelia, Fimax Publicistas, 1989.

Warren, J. Benedict y Cristina Monzón, “Carta de los principales de Pátzcuaro al obispo Vasco de Quiroga. 10 de marzo de 1549”, en Relaciones. Estudios de Historia y Sociedad, núm. 99, vol. xxv, 2004, 177-211.

FECHA DE RECEPCiÓn DEL ARTÍCUlO: 27 de septiembre de 2010 FECHA DE ACEPTACIÓN Y RECEPCIÓN DE LA VERSIÓN FINAL: 9 de febrero de 2011 